\title{
Cyclic Nucleotide-Mediated Regulation of Hippocampal Mossy Fiber Development: A Target-Specific Guidance
}

\author{
Satomi Mizuhashi, Nobuyoshi Nishiyama, Norio Matsuki, and Yuji Ikegaya \\ Laboratory of Chemical Pharmacology, Graduate School of Pharmaceutical Sciences, The University of Tokyo, \\ Tokyo 113-0033, Japan
}

\begin{abstract}
The mossy fibers (MFs) arising from dentate granule cells project primarily onto a narrow segment of the proximal dendrites of hippocampal CA3 pyramidal cells. The mechanisms underlying this specific MF target selection are not fully understood. To investigate the cellular basis for development of the stereotyped MF trajectories, we have arranged the fascia dentata and hippocampal Ammon's horn tissues in diverse topographical patterns in organotypic explant coculture systems. Here we show that cyclic nucleotide signaling pathways regulate the MF pathfinding. When the dentate gyrus explants were ectopically placed facing the CA3 stratum oriens of hippocampal slices, MFs crossed the border between cocultures and reached their appropriate target area in the Ammon's horn, as assessed by membrane tracer labeling, Timm staining, electrophysiological recording of synaptic responses, and optical analyses using a voltage-sensitive dye. This lamina-specific MF
\end{abstract}

The formation of the myriad of neuronal connections within the vertebrate nervous system relies on the correct pathfinding and target recognition by growth cones (Bray and Hollenbeck, 1988; Keynes and Cook, 1995; Tessier-Lavigne and Goodman, 1996). Although diffusible or substrate-bound molecules present in the environment may serve as either attractants or repellents in axon guidance (Gundersen and Barrett, 1979; Bonhoeffer and Huf, 1980; Tessier-Lavigne et al., 1988; Müller, 1999), evidence that axonal behaviors in response to these cue signals are regulated by their intracellular conditions is also accumulating. Cyclic nucleotides have been identified as such key regulators of the growth cone motility. Abdel-Majid et al. (1998) showed that loss of adenylyl cyclase type I activity in mutant mice disrupts patterning of somatosensory cortex, suggesting that the cAMP signaling pathway is involved in network formation during brain development. Wang and Zheng (1998) indicated that the cAMP signaling pathway regulates the neurotrophin-induced collapse of growth cones of Xenopus spinal neurons. Furthermore, levels of cyclic nucleotides influence the direction of growth cone extension in response to the same guidance cue (Ming et al., 1997; Song et al., 1997, 1998).

\footnotetext{
Received Feb. 28, 2001; revised April 30, 2001; accepted June 1, 2001.

This work was supported by research grants from the Fujisawa Foundation and grants-in-aid for scientific research from the Ministry of Education, Science and Culture of Japan.

Correspondence should be addressed to Yuji Ikegaya, Laboratory of Chemical Pharmacology, Graduate School of Pharmaceutical Sciences, The University of Tokyo, 7-3-1 Hongo, Bunkyo-ku, Tokyo 113-0033, Japan. E-mail: ikegaya@tk.airnet.ne.jp.

Copyright (C) 2001 Society for Neuroscience $\quad 0270-6474 / 01 / 216181-14 \$ 15.00 / 0$
}

innervation was disrupted by pharmacological blockade of cGMP pathway. Similar apposition of the dentate grafts near the CA1 region of host slices rarely resulted in MF ingrowth into the Ammon's horn. Under blockade of cAMP pathway, however, the MFs were capable of making allopatric synapses with CA1 neurons. These data were further supported by the pharmacological data obtained from granule cells dispersed over hippocampal slice cultures. Thus, our findings suggest that the stereotyped MF extension is mediated by at least two distinct factors, i.e., an attractant derived from the CA3 region and a repellent from the $\mathrm{CA} 1$ region. These factors may be regulated differently by cAMP and cGMP signaling pathways.

Key words: mossy fiber; axon guidance; hippocampus; dentate gyrus; granule cell; growth cone; adenylyl cyclase; guanylyl cyclase; kinase; extracellular matrix; plasmin
The mossy fibers (MFs), axons of dentate granule cells, make multiple giant synapses with hippocampal CA3 pyramidal cells within the stratum lucidum, which corresponds to the proximal site of the apical dendrites of these neurons (Ramón y Cajal, 1911; Amaral and Dent, 1981; Henze et al., 2000). The granule cells have the unusual property of prolonged postnatal neurogenesis that persists into adulthood in rodents (Altman and Das, 1965; Kaplan and Hinds, 1977; Kuhn et al., 1996) and other mammalian species, including humans (Eckenhoff and Rakic, 1988; Eriksson et al., 1998). Therefore, the pathfinding by developing MFs from newly born granule cells also continues for a lifetime.

The granule cells are also thought to play a role in the pathogenesis of temporal lobe epilepsy, in which they often give rise to abnormal MF projections to the inner molecular layer of the dentate gyrus (DG) and to the basal dendrites of CA3 pyramidal cells in the stratum oriens (Sutula et al., 1989; Represa and Ben-Ari, 1992). This aberrant sprouting may involve anomalous guidance of developing MFs (Parent et al., 1997; Ikegaya, 1999). Therefore, elucidating the mechanisms for MF pathfinding is not only of fundamental importance to understand the physiological functions of the adult hippocampus but may also provide novel therapeutic targets against epilepsy-associated brain injury.

Several extracellular molecules are known to mediate MF outgrowth, including limbic system-associated membrane protein (Pimenta et al., 1995), polysialylated neural cell adhesion molecule (Muller et al., 1994; Seki and Rutishauser, 1998), neuropilin-2, and Sema3F (Chen et al., 2000). Proteolytic processes by tissue plasminogen activator may also be involved in MF synaptogenesis (Baranes et al., 1998; Wu et al., 2000). How- 
ever, there are few indications for intracellular mechanisms underlying MF development. Therefore, we have focused the present study on the contributions of $\mathrm{cAMP} / \mathrm{cGMP}$ signaling pathways to the MF guidance.

\section{MATERIALS AND METHODS}

Materials. 9-(Tetrahydro-2-furanyl)-9H-purin-6-amine (SQ22536), forskolin, plasmin, Rp-8(4-chlorophenylthio)guanosine-3',5'-cyclicmonophosphorothioate triethylamine (Rp-pCPT-cGMPs), and LY83583 were purchased from Sigma (St. Louis, MO). Rp-adenosine 3'-5'-cyclic monophosphorothioate (Rp-cAMPs) was obtained from Biolog Life Technologies (Glasgow, UK). KT-5720 was obtained from Biomol Research Laboratories (Plymouth Meeting, PA).

Organotypic cultures of hippocampal slices. Hippocampal slice cultures were prepared from 6-d-old Wistar/ST rats (SLC, Shizuoka, Japan), essentially as described (Ikegaya, 1999). Animals were deeply anesthetized by hypothermia, and their brains were aseptically removed and cut into transverse slices (300 $\mu \mathrm{m}$ thick) in aerated $\left(95 \% \mathrm{O}_{2}\right.$ and $\left.5 \% \mathrm{CO}_{2}\right)$, ice-cold Gey's balanced salt solution supplemented with $25 \mathrm{~mm}$ glucose using the Vibratome DTK-1500 (Dosaka, Kyoto, Japan). The entorhinohippocampi were dissected out under stereomicroscopic control. Then, selected slices were cultured using membrane interface techniques (Stoppini et al., 1991). Briefly, slices were placed on sterile polytetrafluoroethylene membranes (Millicell-CM, Millipore, Bedford, MA) and transferred into six-well tissue culture trays (Costar, Cambridge, MA). Cultures were fed with $1 \mathrm{ml}$ of culture medium consisting of $50 \%$ minimal essential medium (Life Technologies, Grand Island, NY), 25\% heat-inactivated horse serum (Cell Culture Lab, Cleveland, OH), and $25 \%$ Hanks' balanced salt solution, supplemented with $25 \mathrm{~mm}$ glucose, 50 $\mathrm{U} / \mathrm{ml}$ penicillin $\mathrm{G}$, and $100 \mu \mathrm{g} / \mathrm{ml}$ streptomycin. The cultures were maintained in a humidified incubator at $37^{\circ} \mathrm{C}$ in $5 \% \mathrm{CO}_{2}$. The medium was changed every $3.5 \mathrm{~d}$.

Coculture system of DG explants and hippocampal slices. Acute entorhino-hippocampal slice was prepared as described above, and the fascia dentata with hilus and a small part of the CA3c region was isolated from the hippocampal Ammon's horn. A small, curved scalpel was used to make a cut through the entire thickness of the slice. The stumps were cocultured in various spatial patterns (see Fig. 2). They were placed as close to each other as possible, preferably without a visible intervening gap, and with the dentate hilus and the attached proximal part of CA3 directly facing host hippocampal slices. The DG-containing slice was reopposed immediately adjacent to $\mathrm{CA} 3$ transection like an intact slice (see Fig. 2B, Lesion). The DG slice was ectopically explanted facing the stratum oriens of the CA3 (see Fig. $2 C, D, D G \& C A 3)$ or CA1 $(D G \&$ $C A 1)$ region of an Ammon's horn slice. The DG slice was located close to each CA3 transection of two symmetrically placed hippocampal slices (see Fig. 2E, DG\& Double CA3). The CA3 region of Ammon's horn slice was apposed along the stratum oriens of the $\mathrm{CA} 3$ region of an intact slice (see Fig. $2 F, D G$ with $C A 3 \& C A 3$ ). The DG explant was placed facing the stratum oriens of the CA3 region of an intact slice (see Fig. $2 G, D G$ \& $C A 3$ with $D G)$. The cocultures were kept in a humidified incubator at $37^{\circ} \mathrm{C}$ in $5 \% \mathrm{CO}_{2}$ (Zimmer and Gähwiler, 1987; Gaiarsa and Heimrich, 1995). The medium was changed every $3.5 \mathrm{~d}$. Unless specified otherwise, experiments were performed after $14 \mathrm{~d}$ in vitro.

Astrocyte-conditioned medium. Glial cells were cultured in Eagle's medium (Nissui Pharmaceuticals, Tokyo, Japan) containing $30 \mathrm{~mm}$ glucose, $2 \mathrm{~mm}$ glutamine, $1 \mathrm{~mm}$ pyruvate, and $10 \%$ fetal bovine serum (Sanko-Junyaku, Tokyo, Japan). Astrocyte-conditioned medium was prepared from cultures of cortical astrocytes. Neonatal Wistar (SLC) rats were deeply anesthetized with ether, and the cerebral cortex was dissected out and cut into pieces. After incubation with $0.25 \%$ trypsin (Difco, Detroit, MI) and 0.01\% deoxyribonuclease I (DNase I) (Sigma) at $37^{\circ} \mathrm{C}$ for $40 \mathrm{~min}$, the tissue was centrifuged at $1200 \mathrm{rpm}$ for $5 \mathrm{~min}$, and the pellet was resuspended in Eagle's medium. Single cells were mechanically dissociated by being passed 5-12 times through a plastic tip with an $850 \mu \mathrm{m}$ hole. After filtration through double nylon nets ( $45 \mu \mathrm{m}$ mesh) to remove cell lumps, the suspension was diluted to the optimal concentration, and cells were plated on $75 \mathrm{~cm}^{2}$ culture flasks (Falcon, Oxnard, CA) at a density of $6.0 \times 10^{5}$ cells $/ \mathrm{cm}^{2}$ and then cultivated at $37^{\circ} \mathrm{C}$ in a humidified $5 \% \mathrm{CO}_{2}$ and $95 \%$ air atmosphere. As the culture became confluent, the medium was conditioned for $3 \mathrm{~d}$, filtrated through $0.22 \mu \mathrm{m}$ pore membrane, and subsequently used for neuron culture as astrocyteconditioned medium.
Primary cultures of granule cells. Unless specified otherwise, neurons were cultivated in Neurobasal (Life Technologies, Gaithersburg, MD) supplemented with $73 \mu \mathrm{g} / \mathrm{ml}$ L-glutamine and $2 \%$ (v/v) B-27 supplement (Life Technologies). Three-day-old Wistar rat pups (SLC) were deeply anesthetized with ether, the formatio hippocampalis was immediately removed, and the DG was isolated with extreme care before dissociation so that cultures contained neurons predominantly from this part of the hippocampal formation. Briefly, after isolation of the formatio hippocampalis, the subicular complex was removed along the sulcus hippocampi, and then the remaining part of the formatio hippocampalis was divided into two parts, i.e., the DG and the Ammon's horn. The DG was cut into pieces and treated with trypsin and DNase I at $37^{\circ} \mathrm{C}$ for $30 \mathrm{~min}$. The incubation was terminated by addition of heat-inactivated horse serum (Cell Culture Lab). The tissue fragments were centrif uged at 1200 rpm for $5 \mathrm{~min}$, the supernatant was removed, and the pellet was suspended in a mixture of $50 \%$ Neurobasal/B-27 and 50\% astrocyteconditioned medium. The suspension was gently triturated until visibly dispersed, followed by being filtered through nylon nets. We were able to obtain $\sim 5.0 \times 10^{5}$ granule cells from one pup. The cells were plated at a density of $1.0 \times 10^{4}$ cells $/ \mathrm{cm}^{2}$ onto $35 \mathrm{~mm}$ culture dishes (Falcon) coated with poly-D-lysine (Sigma) and cultivated at $37^{\circ} \mathrm{C}$ in a humidified $5 \% \mathrm{CO}_{2}$ and $95 \%$ air atmosphere. To prevent proliferation of glial cells, the culture medium was changed to the conditioned medium-free Neurobasal/B-27 medium supplemented with $2 \mu \mathrm{M}$ cytosine $\beta$-Darabino-furanoside (Sigma) $24 \mathrm{hr}$ after the plating.

Slice overlay assay. To obtain a quantitative assessment of MF projections, we labeled granule cells with 1,1'-dioctadecyl 3,3,3' $3^{\prime}$ tetramethylindocarbocyanine perchlorate (DiI) (Molecular Probes, Eugene, OR), a carbocyanine-type membrane tracer (Honig and Hume, 1989). A DiI stock solution of $0.5 \mathrm{mg} / \mathrm{ml}$ was prepared in methanol and stored at $-20^{\circ} \mathrm{C}$. Immediately before use, the stock was diluted $100 \times$ in medium, and this suspension was vortexed continuously for $2 \mathrm{~min}$. Dissociated granule cells were incubated in the DiI suspension at $37^{\circ} \mathrm{C}$ for $30 \mathrm{~min}$. The DiI incubation was terminated by washing cultures back into the culture medium. The cells were plated onto hippocampal Ammon's horn slices devoid of the fascia dentata at a density of $5 \times 10^{5}$ cells/ml (Polleux et al., 1998, 2000). At 3 d in vitro, the morphology of live neurons was observed with the Bio-Rad MRC-1000 confocal imaging system (Bio-Rad Microscience Division, Cambridge, MA), which was equipped with the inverted microscope ECLIPSE TE300 (Nikon, Tokyo, Japan), $40 \times$ and $60 \times$ objectives (Nikon), an argon ion laser, and a host computer system. All imaging and processing operations were performed with Laser Sharp Acquisition (Bio-Rad) and Laser Sharp Processing (Bio-Rad), respectively. The cultures were illuminated with the excitation wavelength of $543 \mathrm{~nm}$, and the fluorescence images were obtained through a $570 \mathrm{~nm}$ long-pass filter. Camera lucida drawings were digitized as black and white photograph quality images. In axonal orientation plots, the axons of granule cells were scored as being directed toward the CA1 stratum pyramidale $\left(0-180^{\circ}\right)$ or toward the CA3 stratum pyramidale $\left(180-360^{\circ}\right)$ on the basis of their orientations.

NeuroTrace fluorescent Nissl staining. Cultures were washed three times in $0.1 \mathrm{M}$ PBS for $5 \mathrm{~min}$ at room temperature and fixed with $4 \%$ paraformaldehyde at $4{ }^{\circ} \mathrm{C}$ for $60 \mathrm{~min}$. After being washed three times in PBS for $15 \mathrm{~min}$, the sections were permeabilized with $0.1 \%$ Triton- $X$ for $60 \mathrm{~min}$, washed again in PBS for $10 \mathrm{~min}$, and then incubated with NeuroTrace fluorescent Nissl (Molecular Probes) (1:30 dilution) for $40 \mathrm{~min}$ in a dark room at room temperature. The incubation was terminated with $10 \mathrm{~min}$ wash in $0.1 \%$ Triton-X, followed by PBS rinse for $2 \mathrm{hr}$ at room temperature, and Nissl-stained sections were observed with a laser scanning confocal system MRC-1000 (Bio-Rad). The cultures were illuminated with the excitation wavelength of $488 \mathrm{~nm}$, and the fluorescence images were obtained through a $530 \mathrm{~nm}$ long-pass filter.

Assessment of cell death. Cell death was assessed by uptake of propidium iodide (PI) (Molecular Probes). PI is a polar compound that enters only cells with damaged membranes and becomes brightly red fluorescent after binding to nucleic acids (Macklis and Madison, 1990). PI was added to culture medium at a final concentration of $5 \mu \mathrm{g} / \mathrm{ml}$, and the cultures were kept at $37^{\circ} \mathrm{C}$ for $24 \mathrm{hr}$. PI fluorescence images were obtained with the confocal imaging system MRC-1000 (Bio-Rad).

Extracellular recording. Cultures on interface membranes were cut out, transferred to a recording chamber mounted on a stereoscopic microscope, and continuously superfused with a warmed $\left(32^{\circ} \mathrm{C}\right)$ artificial CSF (ACSF), which consisted of (in mM): $124 \mathrm{NaCl}, 26 \mathrm{NaHCO}_{3}, 5 \mathrm{KCl}, 1.3$ $\mathrm{MgSO}_{4}, 1.24 \mathrm{KH}_{2} \mathrm{PO}_{4}, 2.4 \mathrm{CaCl}_{2}$, and 10 glucose, adjusted to $\mathrm{pH}$ 7.4. To record an MF synaptic potential, a glass micropipette filled with $0.9 \%$ 
$\mathrm{NaCl}(\sim 1 \mathrm{M} \Omega$ of resistance) was placed in the stratum pyramidale of the CA1 or CA3 region, and a bipolar tungsten stimulating electrode was placed on the stratum granulosum of the DG. The positive field potential (see Fig. $3 A$ ) reflected field EPSP (fEPSP) because it was blocked by $10 \mu \mathrm{M}$ 6-cyano-7-nitroquinoxaline-2,3-dione, a non-NMDA receptor antagonist (Ikegaya, 1999). The intensity of electric stimulation (a rectangular pulse of $50 \mu \mathrm{sec}$ duration) was adjusted to produce fEPSP with the maximum amplitude. The test stimulation was delivered every $30 \mathrm{sec}$. The maximal size of fEPSP was used as an index of the number of functional synaptic contacts of MFs (Muller et al., 1993; Ikegaya et al., 1997).

Timm staining. After PBS rinse, slices were immersed in $0.4 \%$ sodium sulfide solution at $4^{\circ} \mathrm{C}$ for $15 \mathrm{~min}$ and fixed with $10 \%(\mathrm{v} / \mathrm{v})$ formaldehyde for $15 \mathrm{~min}$. After being washed in PBS, they were dehydrated with 70 and $96 \%$ ethanol twice for $30 \mathrm{~min}$ and then dried. To perform silver sulfide staining, the slices were incubated with citrate-buffered solution containing 20\% Arabic gum, 2.1\% $\mathrm{AgNO}_{3}$, and $0.085 \%$ hydroquinone in a dark room at $26^{\circ} \mathrm{C}$ for $50 \mathrm{~min}$. The slices were washed with distilled water at the end of the reaction. To quantify MF terminals, the images were digitized with FinePix S1Pro (Fuji Photo Film, Tokyo, Japan) equipped with a bright-field microscope. Average pixel intensity (eight-bit intensity levels) was estimated in each slice by acquiring intensity values in three different areas $(3 \times$ $400 \mu \mathrm{m}^{2}$ ) within the CA3 stratum oriens, the stratum radiatum, the CA3 stratum pyramidale, the stratum lucidum, the CA1 stratum pyramidale, and the CA1 stratum oriens. Timm grain density in each subregion was determined by (values of the subregion - values of the stratum radiatum)/values of the stratum radiatum $\times 100$.

DiI labeling of MF tracts. Slices were fixed with PBS containing 4\% paraformaldehyde for $24 \mathrm{hr}$, and a single crystal ( $\sim 0.1 \mathrm{~mm}$ diameter $)$ of the fluorescent membrane tracer DiI was carefully inserted into the stratum granulosum of the DG under a dissecting microscope. This procedure resulted in random labeling of a small proportion of the granule cells, but each neuron was labeled throughout the soma and its neurites. Thus, the method allowed a reliable observation of individual MF tracts. After $3 \mathrm{~d}$ of incubation in the same fixative at room temperature, MF morphology was analyzed using the confocal imaging system MRC-1000 (Bio-Rad) with a $60 \times$ objective (Nikon) and a digital zoom factor of 1 to 3 .

Voltage-sensitive dye measurement. For optical recordings, the cultures were bath labeled with the voltage-sensitive dye RH482 (2 mg/ml) (Nippon Kankoh-Shikiso, Okayama, Japan) for $5 \mathrm{~min}$ and then washed in ACSF for at least $15 \mathrm{~min}$. Transmitted light with the wavelength of $700 \pm$ $20 \mathrm{~nm}$ was projected, and optical data were obtained with a $128 \times 128$ photodiode array at a frame rate of $0.6 \mathrm{msec}$. Sixteen successive trial images $\left(600 \mathrm{msec}\right.$ duration, $\left.5.08 \mathrm{~mm}^{2}\right)$ were averaged to improve the signal-to-noise ratio (Nakagami et al., 1997).

Immunofluorescence imaging. Cultured dentate granule cells were immunolabeled with mouse monoclonal antibody against growth coneassociated protein 43 (GAP-43) (Sigma) and rabbit polyclonal antibody against all isoforms of adenylyl cyclase (Santa Cruz Biotechnology, Santa Cruz, CA). At $3 \mathrm{~d}$ in vitro, they were washed in PBS at room temperature, immersed in ice-cold $4 \%$ paraformaldehyde in PBS, and fixed for $60 \mathrm{~min}$. The cells were then washed three times in PBS, permeabilized with $0.1 \%$ Triton X-100 in PBS for 60 min at room temperature, and then washed three times in PBS again. Nonspecific antibody binding was blocked by incubation in 2\% horse serum in PBS for 120 min at room temperature. Without washing, the cultures were incubated overnight at $4^{\circ} \mathrm{C}$ with primary antibodies to GAP-43 (1:1000) and adenylyl cyclase (1:400). They were washed three times in PBS and incubated with Texas Redconjugated anti-mouse IgG (1:1000) (Sigma) and fluorescein isothiocyanate-conjugated anti-rabbit IgG (1:30) (Sigma) at $4^{\circ} \mathrm{C}$ for $4 \mathrm{hr}$. Immunofluorescent preparations were then washed three times in PBS again. Images were obtained with the confocal imaging system MRC1000 (Bio-Rad).

Statistics. Data were analyzed by $\chi^{2}$ test in Figures $1 C$ and $7 B$. All other data are expressed as means \pm SEM values. Tests of variance homogeneity, normality, and distribution were performed to ensure that the assumptions required for standard parametric ANOVA were satisfied. Statistical analysis was performed by one-way repeated-measures ANOVA and post hoc Tukey's test for multiple pairwise comparisons. Significance was set at the $p<0.05$ level.

\section{RESULTS}

\section{Slice overlay assay of MF orientation}

To assess the effect of local extracellular signals present in the hippocampus on axon guidance of MFs, DiI-labeled dentate granule cells were plated onto hippocampal slices in culture. The morphology of neurons growing over the slices was observed $3 \mathrm{~d}$ after the plating (Fig. 1). On the basis of their locations, the neurons were divided into three groups (Fig. $1 B$ ): neurons growing near the CA1 stratum pyramidale (CA1 area), neurons growing in the area far from the CA1 or CA3 stratum pyramidale (neutral area), and neurons growing near the CA3 stratum pyramidale (CA3 area). More than $90 \%$ of the labeled cells had extended neurites that could be clearly scored for length $(>20$ $\mu \mathrm{m})$ and orientation. Although the cultures were immunostained with an antibody against tau-1 or microtubule-associated protein 2, we could not discriminate between axons and dendrites of the granule cells because of high levels of background immunoreactivities of axons or dendrites derived from hippocampal slices. Therefore, the longest neurites of cultured granule cells were regarded as the MF axons (Ikegaya et al., 1998; Polleux et al., 1998), and they were traced and scored for orientation (Fig. 1C). Quantitative analyses indicated that $74.2 \%$ of MFs growing in the CA1 area were directed toward the CA3 region, and the remaining $25.8 \%$ were directed toward the CA1 stratum pyramidale (Fig. $1 \mathrm{Ca}$ ). Similar results were obtained for the granule cells growing in the CA3 area: $77.1 \%$ were attracted toward the CA3 stratum lucidum, and $22.9 \%$ were directed toward the CA1 region (Fig. 1Cc). Thus, an extracellular signal present in the Ammon's horn may be responsible for the directed MF outgrowth on hippocampal slices. Interestingly, neurons growing in the neutral area far from the CA1 or CA3 stratum pyramidale did not show such oriented axon growth (Fig. $1 C b$ ), which suggests that this area is not influenced by the extracellular guidance signal. Therefore, it seems likely that the MF guidance is mediated by at least two independent factors, i.e., an attractant derived from the CA3 region and a repellent from the CA1 region.

\section{Target specificity of MF projections in explant coculture system}

In the slice overlay assay, the MFs growing in the CA3 area preferentially extended into the CA3 stratum lucidum but soon halted therein, although the normal MFs run horizontally within the stratum lucidum. This inconsistency may be merely attributable to the culture period as short as $3 \mathrm{~d}$, but the possibility that the slice overlay assay does not completely provide physiological environment cannot be ruled out. Therefore, we next addressed the target-specific guidance of MFs using organotypic cocultures of fascia dentata explants and hippocampal Ammon's horn slices. To examine the topographic patterns of MF trajectories in detail, various spatial arrangements of cocultures were prepared as shown in Figure 2. Fluoro-Nissl staining showed that, in this coculture system, neurons survived until at least $21 \mathrm{~d}$ in vitro (Fig. 2). PI labeling also confirmed the same results (data not shown). The neural connectivity of MFs between DG grafts and host hippocampal tissues was assessed by recording field potentials of synaptic responses (Fig. 3). When DG explants were transplanted to hippocampal slices at a regular position and cultivated for $14 \mathrm{~d}$ in vitro (Fig. $2 B$, Lesion), robust $\mathrm{MF}$ synaptic potentials were recorded from the CA3 region of host Ammon's horn slices (Fig. $3)$. The amplitude was comparable to that recorded from intact slices (Figs. 2A, 3). The data suggest that the MFs crossed the border between cocultures and made electrophysiologically func- 


\section{A a}

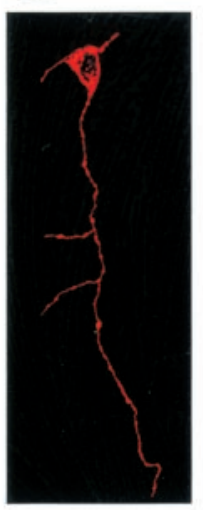

b

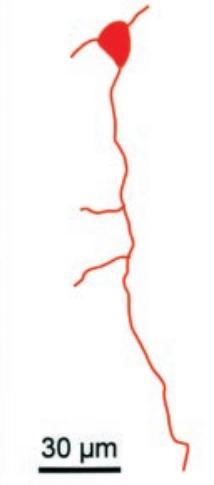

\section{B}

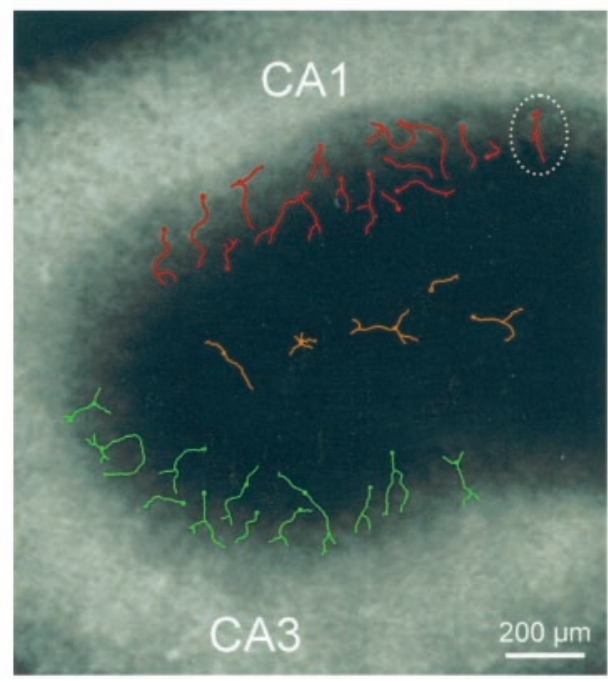

\section{C a CA1 area}

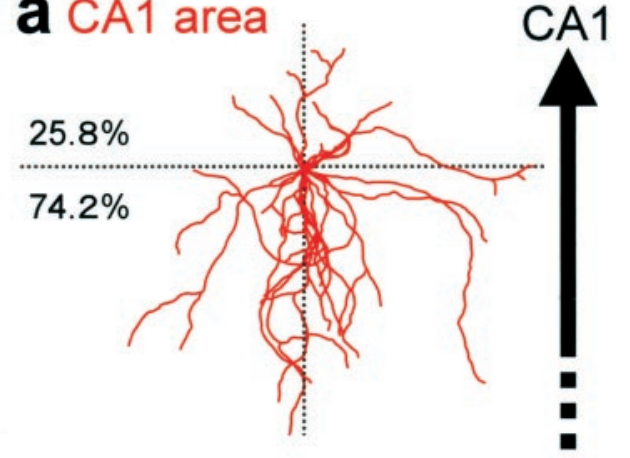

b Neutral area

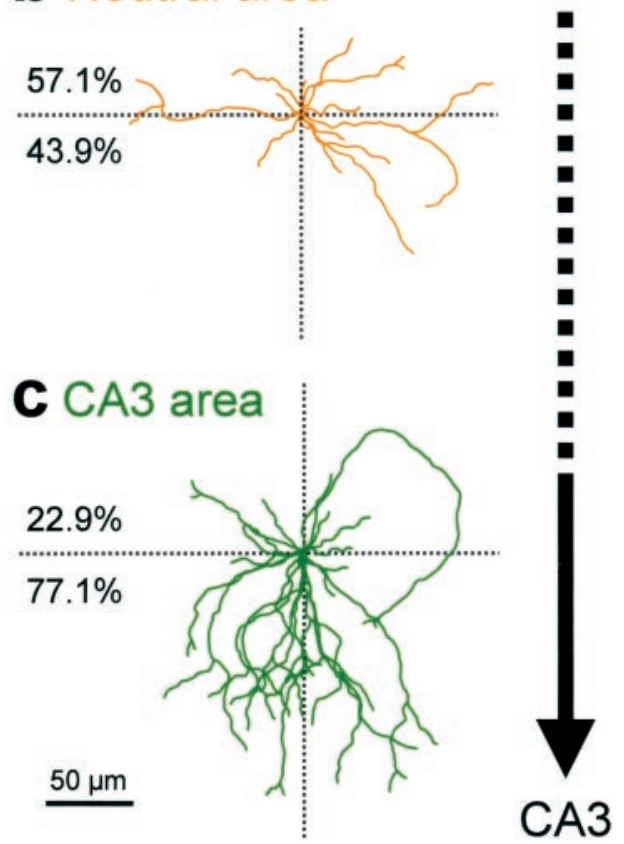

Figure 1. Extracellular signals present in hippocampal slices determine directions of MF outgrowth. $A$, Representative confocal image of DiI-labeled granule cell growing over the CA1 region of a hippocampal slice at $3 \mathrm{~d}$ in vitro $(a)$. This neuron was reconstructed with camera lucida drawings as black and white photograph quality images $(b) . B$, The camera lucida drawings of DiI-labeled granule cells are practically superimposed on a Nissl-stained hippocampal slice. Cells with the somata situated within $200 \mu \mathrm{m}$ from the CA1 stratum pyramidale (red, $C A 1$ area), in the area far from the stratum pyramidale $(>400 \mu \mathrm{m})$ (yellow, Neutral area), or within $200 \mu \mathrm{m}$ from the CA3 stratum pyramidale (green, CA3 area) were selected for analyzing their morphology (52.2\% of total cells were suitable for the analysis). Then, their neurites were scored for length, and the cells bearing $>20 \mu \mathrm{m}$ axons were further selected for axon orientation plots $(\sim 90 \%$ were selected). As a result, $\sim 53 \%$ of the neurons were excluded from this analysis. The neuron enclosed in the white dotted line is the same cell as in $A$. $C$, Axon orientation plots of granule cells plated over the CA1 area $(a)$, the neutral area $(b)$, and the CA3 area $(c)$ of hippocampal slices. The longest neurites arising from cultured cells were plotted as axons in each panel. When the tip of any given neurite was placed above and below the horizontal dotted lines, the axon was considered to grow toward the CA1 stratum pyramidale and the CA3 stratum lucidum, respectively. Thus, values above and below the horizontal dotted lines indicate the ratio of axons oriented toward the CA1 stratum pyramidale and the CA3 stratum lucidum, respectively. Granule cells growing over the CA1 area had axons oriented away from the CA1 stratum pyramidale $\left(74.2 \% ; n=32 ; p<0.05 ; \chi^{2}\right.$ test). In the CA3 area, $77.1 \%$ had axons that were directed toward the CA3 stratum lucidum $(n=35 ; p<0.05$; $\chi^{2}$ test). Granule cells in the neutral area showed an expected ratio for random orientation $(\sim 50 \%)\left(n=14 ; p>0.1 ; \chi^{2}\right.$ test $)$. The results suggest that the axon orientation is mediated by at least two distinct factors, i.e., an attractant in the CA3 region and a repellent in the CA1 region. Data were obtained from six different slices.

tional synapses with their appropriate target neurons, i.e., the CA3 pyramidale cells. This result confirms previous reports indicating that the MFs are able to reestablish their lamina-specific innervation after being transected (Zimmer and Gähwiler, 1987; Dailey et al., 1994; Nguyen et al., 1996; Ikegaya et al., 1997, 1998).

The DG explant was ectopically placed adjacent to the CA3 stratum oriens of Ammon's horn slice, in which MFs were forced to cross the stratum oriens to reach the their proper target area (Fig. $2 C, D G \& C A 3$ ). This arrangement of cocultures also showed evident MF synaptic responses (Fig. 3), which indicates that the MFs were guided into the host slices and made synaptic contacts with their target cells even when the normal MF course was disrupted. In a similar apposition of the DG explant to the CA1 stratum oriens (Fig. 2D, $D G \& C A 1$ ), however, MF responses were virtually undetected in the host CA1 region (Fig. 3), nor were they observed in the host CA3 region (data not shown). These results indicate that MFs are capable of making functional synapses with the CA3 pyramidale cells, but the CA1 region is not permissive for MF invasion, suggesting that MF extension is strictly target dependent. 
A Intact
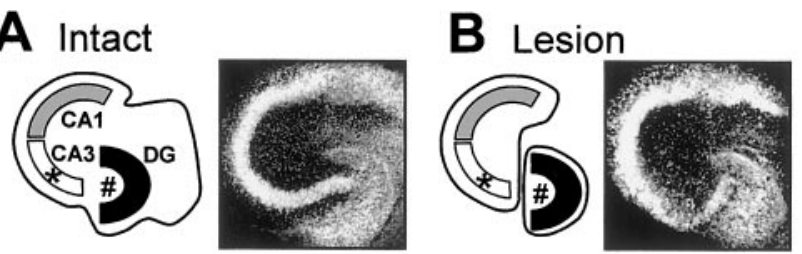

C DG \& CA3
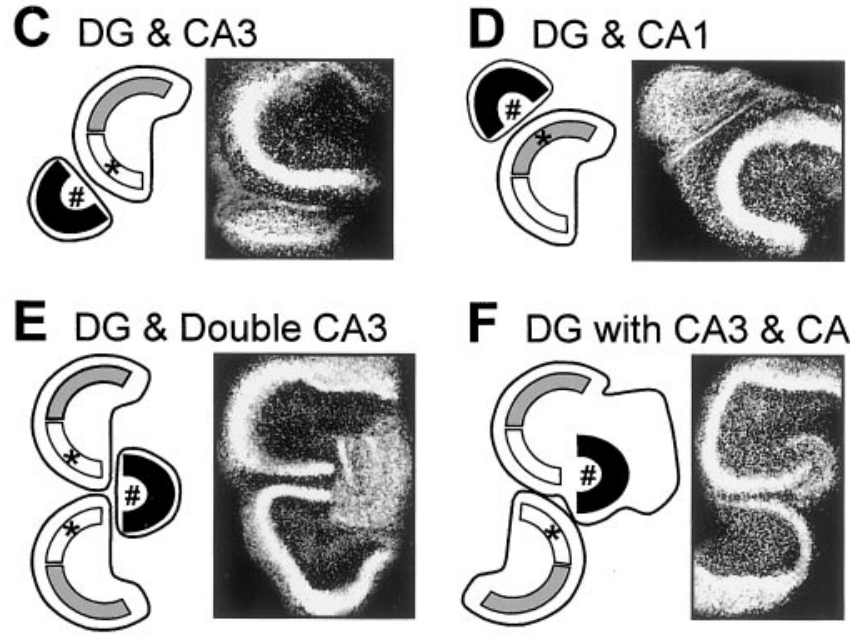

F DG with CA3 \& CA3

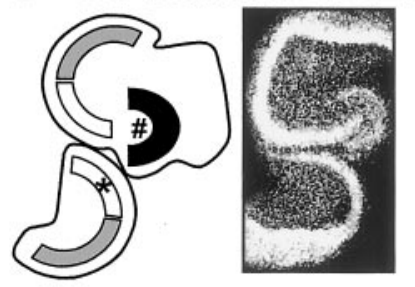

\section{G DG \& DG with CA3}
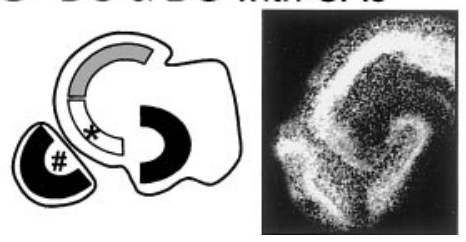

Figure 2. Explant cocultures of the fascia dentata and hippocampal Ammon's horn in various topographic arrangements. Tissues arranged as shown in schematic diagrams (left) were stained with the fluoro-Nissl method (right) at $21 \mathrm{~d}$ in vitro. $A$, An intact slice containing the fascia dentata and Ammon's horn was cultured for $21 \mathrm{~d}$. $B$, As a control slice, the MF layer was transected by a knife cut through the slices reaching from the alvear surface of CA3 through the stratum oriens, the stratum pyramidale, and the MF layer, and the stratum radiatum into the sulcus hippocampi (Lesion). C, The DG explant was ectopically placed close to the CA3 stratum oriens of an Ammon's horn slice, in which the MFs were forced to cross the stratum oriens to reach their proper target area $(D G$ $\& C A 3)$. $D$, Likewise, another dislocated apposition of the DG explant to hippocampal slice at the CA1 stratum oriens was also made ( $D G \& C A 1)$. $E$, The DG slice was located immediately adjacent to two symmetrically arranged hippocampal slices $(D G \&$ Double $C A 3) . F$, The CA3 region of the Ammon's horn slice was apposed along the CA3 stratum oriens and the DG of an intact slice ( $D G$ with $C A 3 \& C A 3)$. $G$, The DG explant was placed facing the stratum oriens of the CA3 region of an intact slice $(D G$ \& $C A 3$ with $D G)$. The Nissl staining revealed that neurons survived in the coculture system until at least $21 \mathrm{~d}$ in vitro. In electrophysiological studies of Figure 3, the stratum granulosum of the DG explant (\#) was stimulated, and evoked field responses were recorded from the stratum pyramidale of Ammon's horn slices (*).

To address this possibility, three additional patterns of cocultures were prepared as shown in Figure $2 E-G$. DG explants were located close to two symmetrically arranged hippocampal slices (Fig. 2E, DG \& Double CA3). Robust MF synaptic potentials appeared in either host slices, and almost equal sizes of the responses were recorded from two CA3 regions (Fig. 3B). Similar results were obtained when the fascia dentata that was not apart from Ammon's horn, i.e., an intact slice, was apposed along the

A a Intact

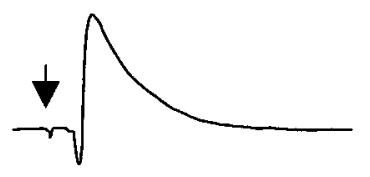

b Lesion
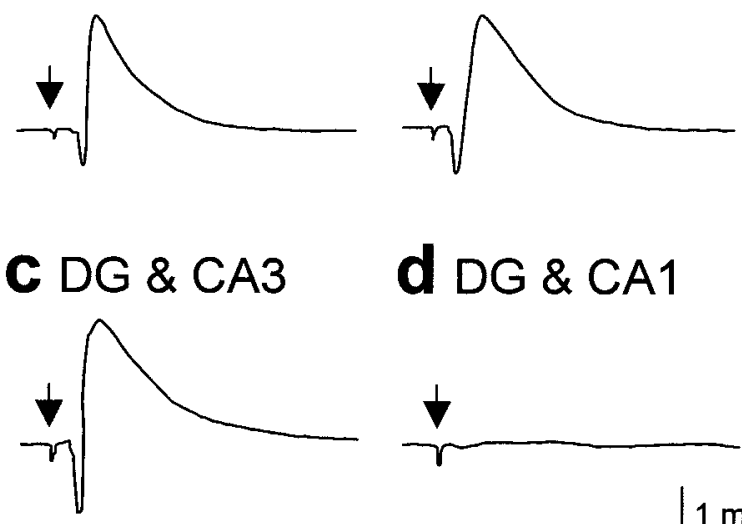

d DG \& CA1
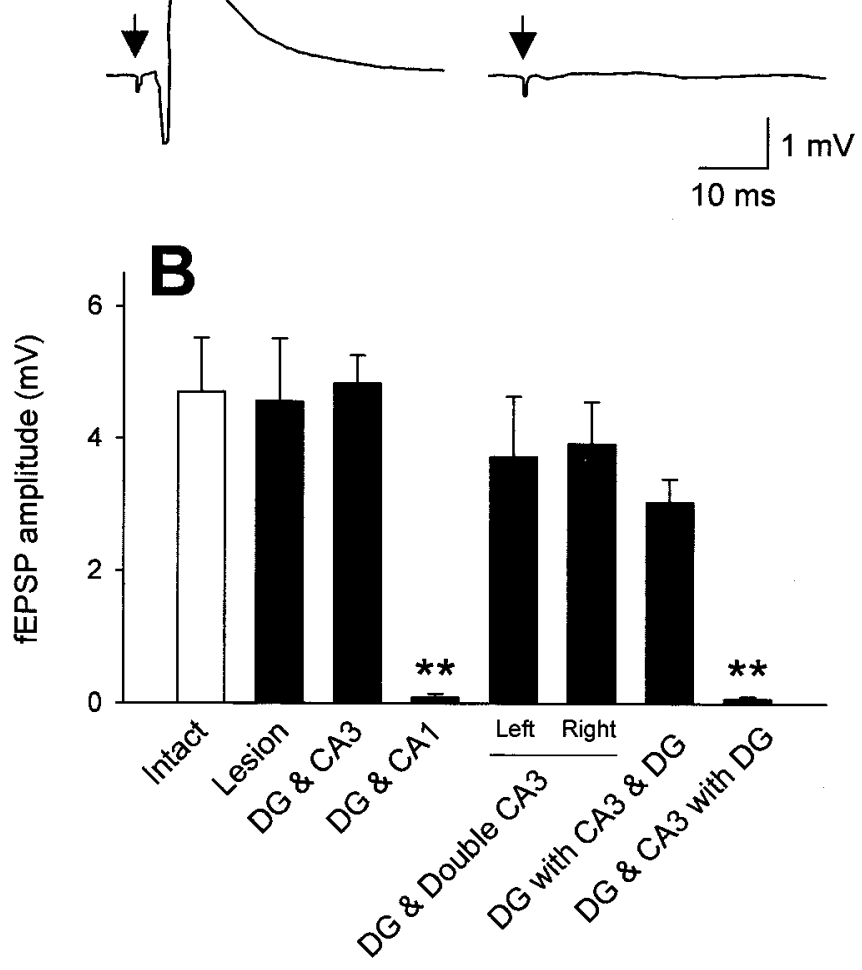

Figure 3. Transplanted MFs make electrophysiologically functional synapses with CA3 pyramidal cells in host hippocampal slices. Field potentials evoked by stimulation of the DG were extracellularly recorded from the CA3 or CA1 stratum pyramidale. Positions of recording and stimulating electrodes are shown in Figure 2. A, Typical field responses obtained from slices cultivated according to Intact $(a)$, Lesion $(b), D G \&$ $C A 3(c)$, and $D G \& C A 1(d)$ at $14 \mathrm{~d}$ in vitro. Test stimulation was delivered at the time indicated by arrows. $B$, To estimate the number of functional synaptic contacts, the maximal amplitudes of MF-evoked fEPSP were measured from various patterns of cocultures (Fig. 2). The MFs made functional synapses with CA3 (but not CA1) pyramidal cells of the host slices, except for the CA3 pyramidal cells that received the MF inputs from the intrinsic DG. ${ }^{*} p<0.01$ versus Intact slices; Tukey's test after ANOVA. Data represent means \pm SEM of each of 15-20 slices.

stratum oriens of the CA3 region of an Ammon's horn slice (Figs. $2 F, 3)$. MF responses were obviously recorded from either the CA3 region of the additional hippocampal slices (Fig. 3) or the intrinsic CA3 region of the intact slices (data not shown). Interestingly, however, no apparent synaptic responses were recorded in the case of the DG explant placed facing the stratum oriens of the CA3 region of an intact slice (Figs. $2 G, 3$ ).

Taken together, these data suggest that newly formed MFs arising from an ectopic origin can normally develop neural connections with their targets but cannot make synapses with the CA3 pyramidal cells that have recipient sites occupied by preex- 

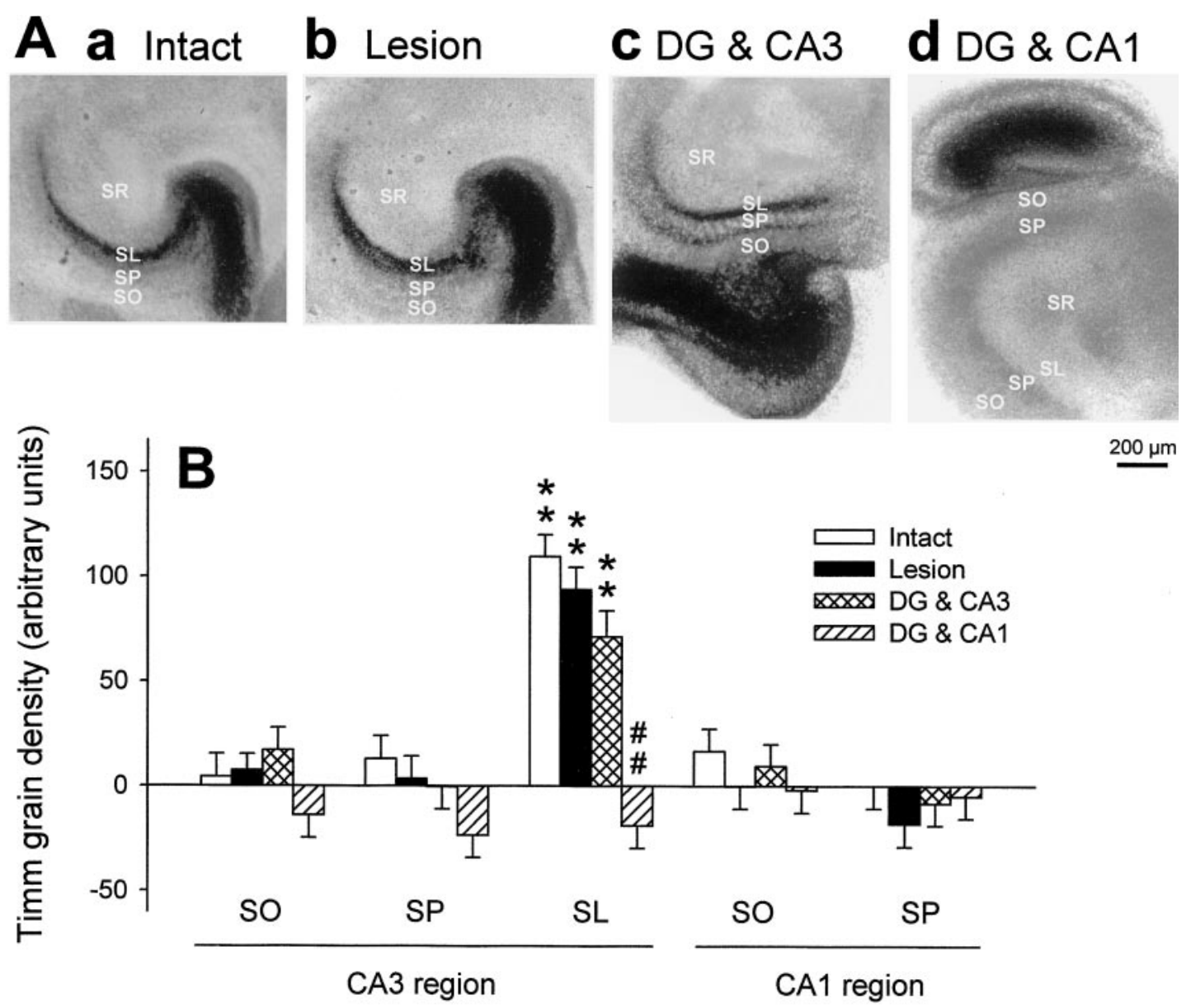

Figure 4. MFs form Timm-positive synapses within their proper target area in host hippocampal slices. $A$, Representative Timm images of slices cultured for $14 \mathrm{~d}$ in patterns of Intact $(a)$, Lesion $(b), D G \& C A 3(c)$, and $D G \& C A 1(d)$. The MF terminals were detected predominantly in the stratum lucidum $(S L)$, but rarely in the stratum oriens $(S O)$ or the stratum pyramidale $(S P)$. The $D G \& C A 1$ culture had no apparent MF terminals in any subregions of the hippocampus. B, Timm grain density was quantitatively analyzed in Intact (open columns), Lesion (solid columns), DG \& CA3 (cross-hatched columns), and $D G \& C A 1$ (hatched columns) cultures. ${ }^{*} p<0.01$ versus background density [values of the stratum radiatum (SR) of corresponding groups], ${ }^{\# \#} p<0.01$ versus Intact slices; Tukey's test after ANOVA. Data are means \pm SEM of each of 10 slices.

isting MF inputs from the intrinsic DG, and again support our hypothesis that MF synapse formation is target dependent.

The Timm method is a histochemical technique that selectively labels MF synaptic terminals because of their high zinc content, ensuring a reliable observation of distributions of MF terminals in organotypic slice cultures (Gähwiler, 1984; Ikegaya et al., 1997; Ikegaya, 1999). The prominent sites innervated by the MFs are the stratum lucidum and dentate hilus, both of which were indeed black-lacquered in Timm-stained intact slices (Fig. 4Aa). Similar patterns of Timm staining were observed in the coculture arrangement of lesion (Fig. 4Ab). The density of Timm-associated silver grains was quantitatively analyzed for subregions of the Ammon's horn in cultures of intact, lesion, DG \& CA3, and DG \& CA1 alignments (Fig. 4B). In DG \& CA3-arranged cultures, a significant Timm intensity was found only in the stratum lucidum of host Ammon's horn slices, which closely resembles Timm staining of intact or lesion-aligned slices (Fig. 4Ac,B). These results suggest that the MFs extending from the DG explant crossed the stratum oriens and the stratum pyramidale and eventually formed MF synaptic contacts within the stratum lucidum, which consequently is reminiscent of naturally occurring development of the MFs. In DG \& CA1-aligned cultures, Timm signals were not obvious in any subregions of Ammon's horn slices (Fig. 4Ad,B), which suggests that such dislocated DG grafts cannot make MF synaptic connections with the host cultures.

The results of Timm staining were essentially compatible with the electrophysiological data, but it still remains to be determined whether the loss of MF synapses in DG \& CA1 cultures is attributable to lack of axon elongation, aberrant axon guidance, or no ability of synaptogenesis. To address this issue, MFs were labeled with the lipophilic tracer DiI.

In intact slices, DiI-labeled MFs traveled within the stratum lucidum and formed several varicosity-like structures, which probably represent MF giant boutons that contact synaptically with the proximal dendrites of CA3 pyramidal cells (Fig. 5A). Indeed, microscopic observations at high magnification revealed that the varicosities often possessed several filopodial formations on their surfaces (data not shown). Likewise, the MFs in a slice of lesion alignment crossed the transit between graft and host, extended into the stratum lucidum, and formed similar giant varicosities therein (Fig. 5B). In DG \& CA3-coordinated cultures, the MFs passed through the stratum oriens and the stratum pyramidale, reached the stratum lucidum, and made varicosities (Fig. 5C). The varicosities were occasionally observed at the border of the stratum oriens and the stratum pyramidale (Fig. $5 C$ ). The incidence of varicosities in each sub-area of the CA3 region is shown in 

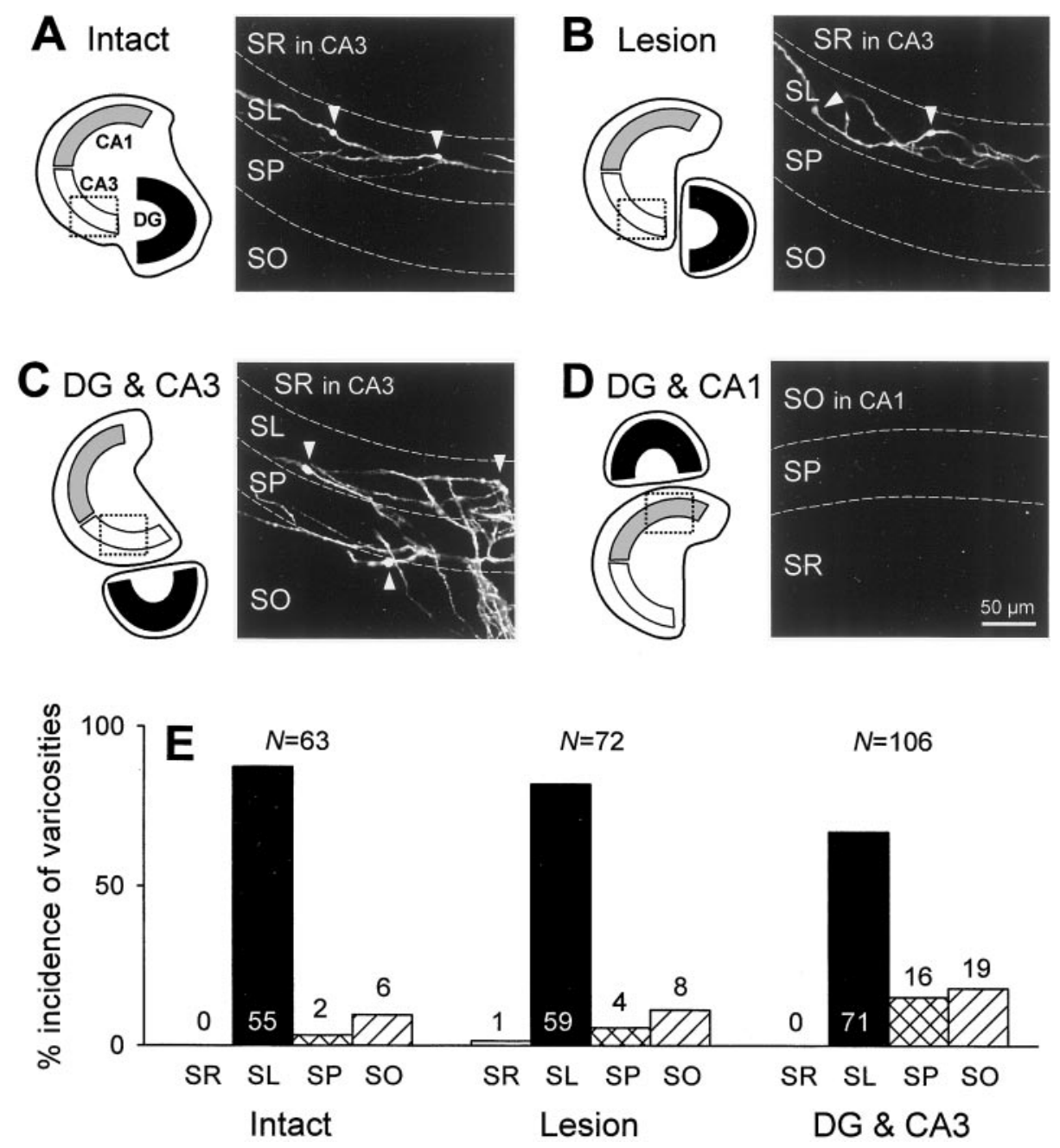

Figure $5 E$. In cultures of DG \& CA1 arrangement, the MFs typically stalled at the border between cocultures and failed to extend into the host slices (Fig. 5D), and a few MFs ran along an alvear edge of the host slices at the CA1 region (data not shown). Therefore, we consider that the MFs cannot come into contact with CA1 pyramidal cells probably because of a repellent signal present in the CA1 region.

Yamamoto et al. (1997) indicated that characteristic patterns of the axonal projection of the lateral geniculate nucleus in the visual cortex are observed even when the geniculocortical explants are cocultured with fixed cortical slices, suggesting that this axon guidance is contact dependent. To determine whether the target-specific MF innervation depends on diff usible or substratebound molecules, Ammon's horn slices were fixed with $4 \%$ paraformaldehyde, and then the DG slices were transplanted in patterns of lesion and DG \& CA3. In either case, however, few DiI-labeled MFs showed ingrowth into the host slices (data not shown).

To examine whether MF projections from DG explants were physiologically capable of producing normal hippocampal neurotransmission along the tri-synaptic pathway consisting of the dentate gyrus, the $\mathrm{CA} 3$ region, and then the CA1 region in the host slices, we monitored spatiotemporal propagations of neuronal activities by using a real-time optical recording of membrane potentials that was visualized with the voltage-sensitive dye RH482. In DG \& CA3 and DG \& double CA3 cocultures, optical

\section{DG \& CA3}

Figure 5. DiI-labeled MFs crossed the border between cocultures and reached their proper target area in hippocampal slices. Cocultures at $14 \mathrm{~d}$ in vitro were fixed with $4 \%$ paraformaldehyde, and a single crystal of DiI was placed onto the stratum granulosum of the DG explant. Using a confocal microscopy, DiIlabeled MFs were explored in the areas indicated by dotted-line boxes in the schematic drawings of Intact $(A)$, Lesion $(B), D G \& C A 3$ $(C)$, and $D G \& C A 1(D)$ cultures. Confocal images contain the stratum radiatum $(S R)$, the stratum lucidum $(S L)$, the stratum pyramidale $(S P)$, and the stratum oriens $(S O)$ of the CA3b region $(A-C)$ or the $\mathrm{CA} 1 \mathrm{~b}$ region $(D)$ of host hippocampal slices. The MFs extended through the stratum lucidum and made varicosity-like formations, which may represent MF giant synapses (arrowheads). In $D G \&$ $C A 3$ slices, the varicosities were occasionally observed within the CA3 stratum oriens. In the case of $D G \& C A 1$, however, the MFs did not elongate into the CA1 region of host hippocampal slices. Similar results were obtained in every such experiment conducted $(n=12$ $20)$. Data are summarized in $E$. The ordinate indicates the relative incidence of distribution of the MF varicosities in each subarea of the CA3 region. Numbers in the columns show the frequency of varicosities present in the corresponding subregions. Most varicosities are observed in the stratum lucidum, but a small portion of them was found even in the stratum pyramidale and stratum oriens in the DG \& $C A 3$ slices. signal propagations along the hippocampal tri-synaptic pathway were distinctively observed after stimulation of the DG explants (Fig. 6B,C), which are similar to those obtained from intact slices (Fig. $6 A$ ). The data indicate that the MFs ectopically arising from the DG explant are able to trigger normal activity propagations in the host Ammon's horn. As expected, the DG \& CA1 slices failed to display apparent neurotransmission from the DG explant to the host slice (Fig. 6D).

\section{cAMP and cGMP signaling pathways differently mediate MF axon guidance}

Although molecular mechanisms of the stereotyped MF pathfinding remain unclear, cyclic nucleotides have been identified as intracellular molecules that regulate growth cone motility in cultured Xenopus spinal neurons (Ming et al., 1997; Song et al., 1997, 1998; Wang and Zheng, 1998). On the other hand, there is compelling evidence that cAMP plays a critical role in physiological functions of mature MF synapses. Activity-dependent changes in MF synaptic efficacy are triggered by a rise in presynaptic $\mathrm{Ca}^{2+}$ that results in activation of a calcium/calmodulindependent adenylyl cyclase. This in turn causes an increase in the presynaptic cAMP level and activation of the cAMP-dependent protein kinase (PKA) (Huang et al., 1994; Weisskopf et al., 1994; Tzounopoulos et al., 1998). Therefore, it is also possible that the $\mathrm{MF}$ development is regulated by the $\mathrm{CAMP} / \mathrm{PKA}$ signaling path- 

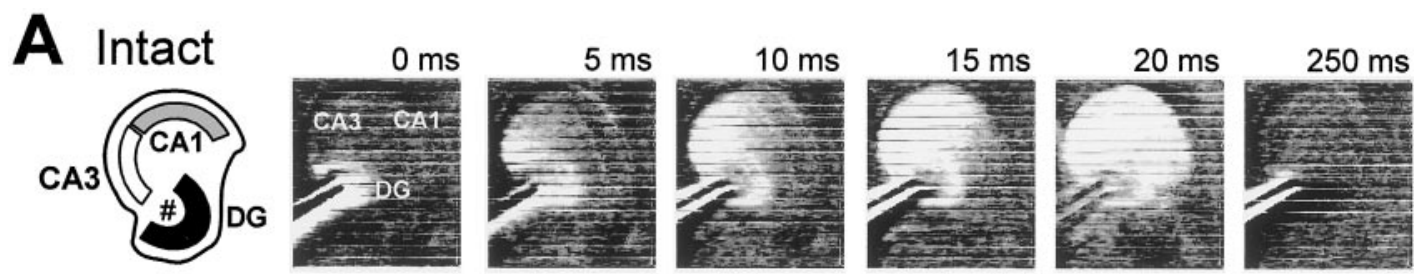

$500 \mu \mathrm{m}$

B DG \& CA3
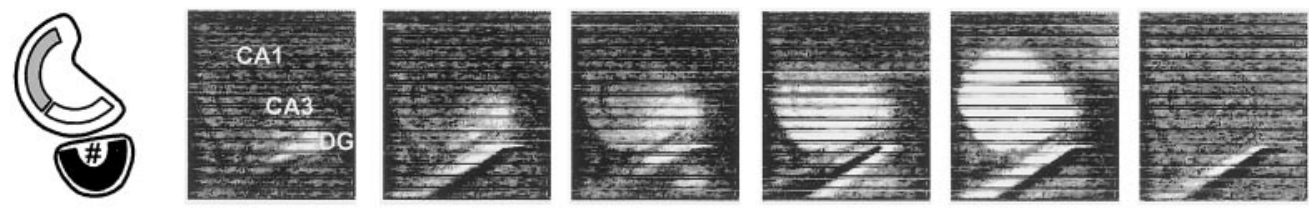

\section{DG \& Double CA3}
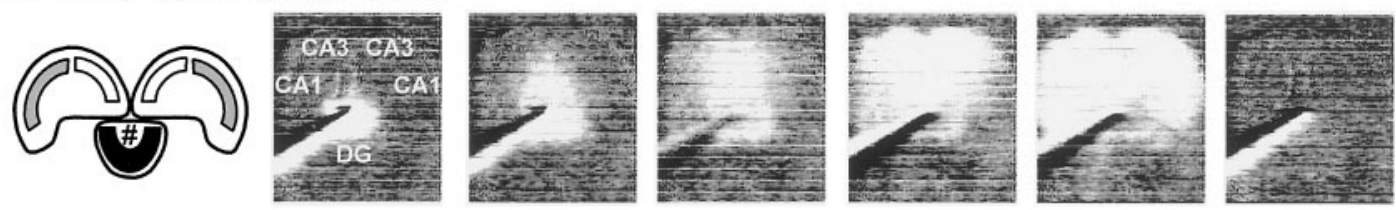

D DG \& CA1
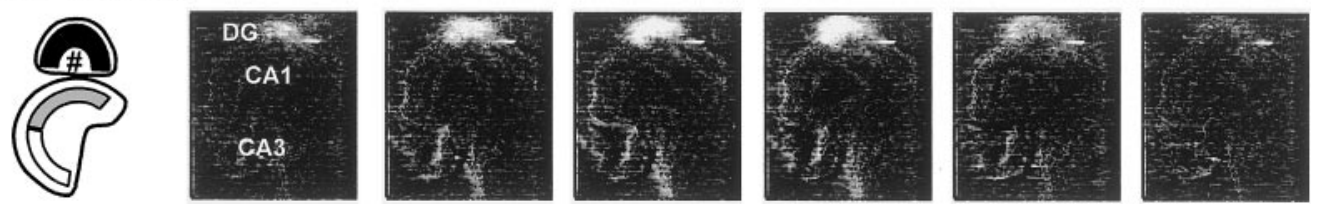

Figure 6. Propagation of neuronal activities from DG grafts to host hippocampal slices. Activity propagation was monitored as changes in optical density of the voltage-sensitive dye RH482. Intact $(A), D G \& C A 3(B)$, and $D G \&$ Double $C A 3(C)$ cultures displayed sequential neuron excitation along the hippocampal trisynaptic pathway, i.e., the dentate gyrus, the CA3 region, and then the CA1 region, after stimulation of the stratum granulosum of the DG explants (\#). No apparent propagation from the DG explant to the host slice was observed in $D G \& C A 1$ slices $(D)$. Experiments were repeated with 10 different slices, producing the same results.

way. In primary cultures of granule cells, indeed, we found that developing MFs bore adenylyl cyclases in their growth cones (Fig. $7 A$ ). Thus, the final set of experiments aimed to evaluate the possible involvement of cyclic nucleotide-dependent signaling pathways in the MF target selection.

Using a slice overlay assay, we investigated the effect of SQ22536, a broad-spectrum inhibitor of adenylyl cyclases, on the axon orientation of granule cells plated over the CA1 area, the neutral area, and the CA3 area of hippocampal slices. SQ22536treated granule cells extended neurites, but their orientation patterns were altered as compared with untreated cells. The MFs of granule cells growing over the CA1 area in the presence of SQ22536 did not grow away from the CA1 stratum pyramidale, but rather they were attracted toward the same layer. In the CA3 area, however, the oriented MF growth was unaffected by SQ22536.

The effect of LY83583, an inhibitor of cGMP-dependent protein kinase (PKG), was also examined. In contrast with SQ22536, LY83583 did not change the MF direction in the CA1 area but completely abolished the attractive responses of the MFs growing over the CA3 area. Actually, in the presence of LY83583, the MFs in this area were almost randomly oriented. SQ22536 or LY83583 had no significant effects on MF behaviors in the neutral area. Incidentally, the neurite elongation of the granule cells was not virtually affected by the treatment with SQ22536 or LY83583; the axon lengths were $123.6 \pm 10.5 \mu \mathrm{m}$ in untreated cells, $115.7 \pm 15.2 \mu \mathrm{m}$ in SQ22536-treated cells, and $122.1 \pm 13.1$ $\mu \mathrm{m}$ in LY83583-treated cells $(p>0.1$; Tukey's test after ANOVA).

We next addressed the possible contribution of cyclic nucleotide signaling pathways to the MF pathfinding by using an explant cocultures system. The cocultures were prepared in DG \& CA3 or DG \& CA1 styles and incubated in the continuous presence of SQ22536 for $14 \mathrm{~d}$ in vitro. Field potentials evoked by stimulation of DG explants were recorded from the CA3 stratum pyramidale of DG \& CA3 cultures or from the CA1 stratum pyramidale of DG \& CA1 cultures. In SQ22536-treated DG \& CA3 cultures, the size of MF synaptic responses was not different from that of control cocultures (Fig. 8), which suggests that pharmacological blockade of adenylyl cyclase did not affect normal MF-CA3 synapse formation. These results were also confirmed in the culture arrangement of intact or lesion (data not shown). Surprisingly, however, robust synaptic responses appeared in the CA1 region of SQ22536-treated DG \& CA1 cultures (Fig. 8), suggesting that reduced cAMP level caused erroneous MF ingrowth into the Ammon's horn, which never occurs naturally. Similar results were obtained for two distinct PKA inhibitors, Rp-cAMPs and KT5720 (Fig. 8). Thus, it seems likely that the cAMP/PKA 

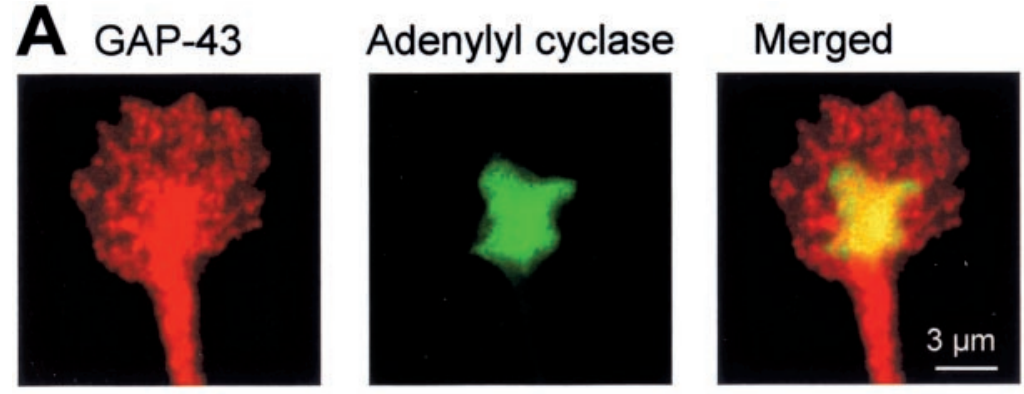

\section{B a CA1 area}

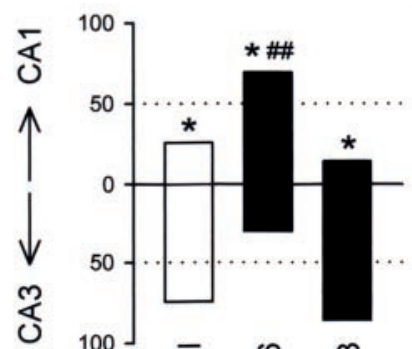

(\%)

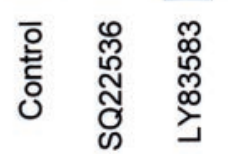

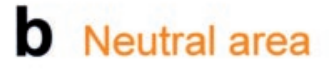
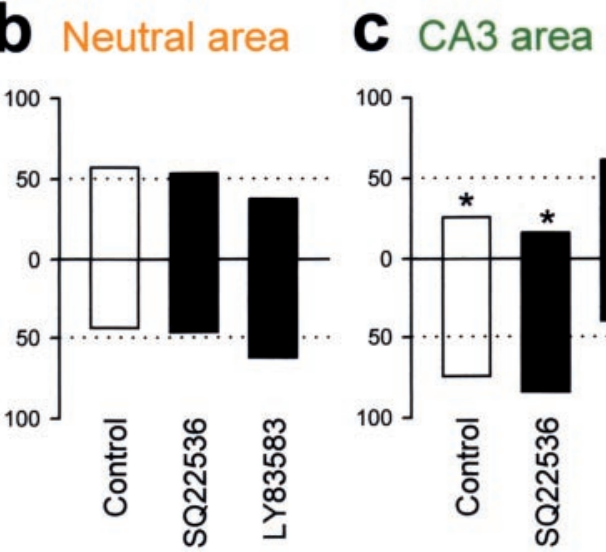

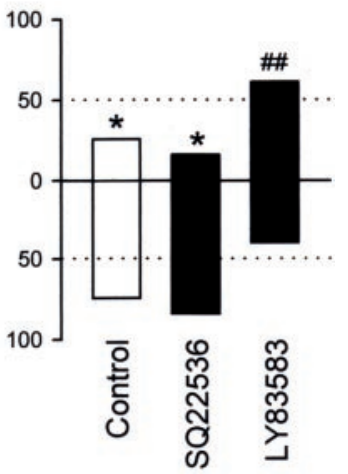

Figure 7. Different contributions of cAMP and cGMP signaling pathways to axon orientation of granule cells. $A$, Representative confocal images of a growth cone immunolabeled with antibodies to GAP-43 (red) and Adenylyl cyclase (green). The immunohistochemical assessment was performed with the dentate granule cells cultured on $35 \mathrm{~mm}$ dishes for $3 \mathrm{~d}$. Superimposition of double-labeled images (Merged) indicated that $\sim 80 \%$ of growth cones displayed evident immunoreactivity for adenylyl cyclase, in which case adenylyl cyclase was localized centrally in the growth cones but apparently not in the peripheral lamellipodia $(n=56)$. $B$, Axon orientation histograms of the granule cells growing over the CA1 area $(a)$, the neutral area $(b)$, and the CA3 area $(c)$. The granule cells were cultured on hippocampal slices in the presence of $100 \mu \mathrm{M}$ SQ22536 and 100 nM LY83583 for $3 \mathrm{~d}$. The upward ordinates indicate the ratio of axons oriented toward the CA1 stratum pyramidale, and the downward ordinates indicate the ratio of axons oriented toward the CA3 stratum lucidum. The repulsive response of the axons of granule cells growing over the CA1 area was converted to attraction by SQ22536. The attractive responses of the axons growing over the CA3 area were disrupted by LY83583. Horizontal dotted lines indicate expected distribution for random orientation. ${ }^{*} p<0.05$ versus the chance level of $50 \%$; ${ }^{\# \# ~} p<0.01$ versus Control slices; $\chi^{2}$ test. Data were obtained from 16-35 neurons in five to six different slices. signaling pathway inhibits the MFs from growing into the inappropriate targets (CA1).

The ectopic MF synapses in SQ22536-treated DG \& CA1 slices were also detected by Timm staining (Fig. 9A), suggesting that these synapses possess characteristic features of the MFs, e.g., high zinc content. Consistent with this is an observation that in SQ22536-treated cocultures, DiI-labeled fibers crossed the CA1 alveus, elongated into the host slices, and made characteristic varicosities in the CA1 region (Fig. 9B). These allopatric varicosities were observed mainly in the CA1 stratum oriens and stratum pyramidale but occasionally in the stratum radiatum. Optical recordings of membrane potentials provided further evidence that under pharmacological blockade of the cAMP signaling pathway, the MFs are able to make functional networks with neurons in the Ammon's horn (Fig. 9C).

Baranes et al. (1998) showed that proteolytic processes via tissue plasminogen activator are involved in MF growth. Because plasmin is one of the principal substrates of this enzyme (Sherry, 1968), we investigated the effect of plasmin on the MF development. Chronic treatment with plasmin caused errant MF synapse formation in the CA1 region of DG \& CA1 cultures without affecting normal synaptogenesis in DG \& CA3 cultures (Fig. 10). Because this effect of plasmin is similar to the allopatric synaptogenesis induced by the lowered cAMP level, we tested the effect of the adenylyl cyclase activator forskolin on plasmin-induced disruption of target-specific MF extension. Interestingly, the effect of plasmin was efficiently attenuated by forskolin (Fig. 10). Incidentally, forskolin per se did not affect the MF pathfinding in DG \& CA3 or DG \& CA1 cultures (Fig. 10). These results also support the hypothesis that the cAMP-activated signaling pathway prevents the MFs from invading inappropriate target areas.

We finally determined whether the cGMP signaling pathway regulates the topographic extension of the MFs. The DG \& CA3 and DG \& CA1 preparations were cultivated for $14 \mathrm{~d}$ in the presence of Rp-pCPT-cGMPs, an inhibitor of all three isoforms of guanylyl cyclases. In contrast with the blockade of adenylyl cyclase, the decreasing cGMP level did not cause aberrant ingrowth of the MFs into the CA1 region of DG \& CA1 cultures but suppressed normal synapse formation onto CA3 pyramidal cells in the

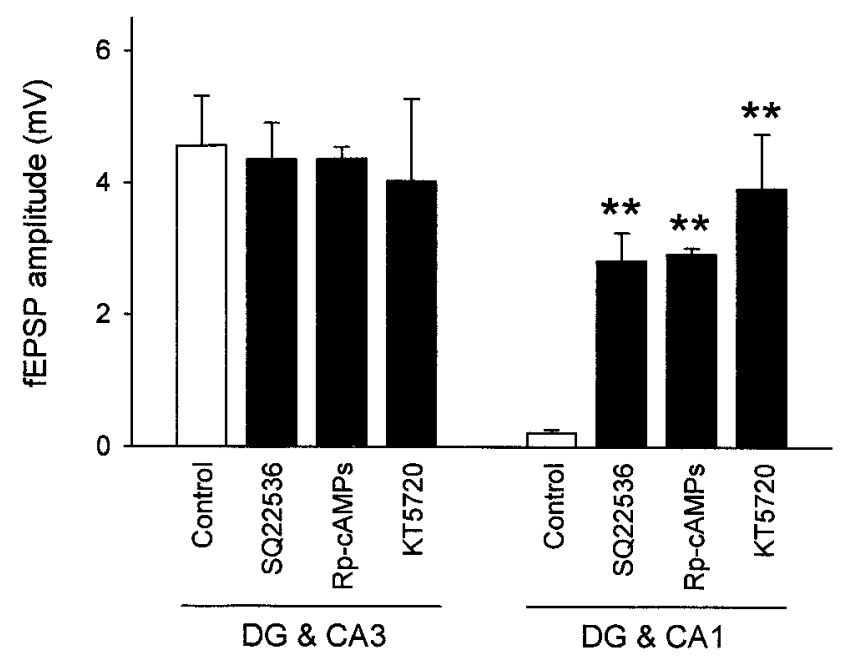

Figure 8. Involvement of the cAMP signaling pathway in MF synaptogenesis. Cocultures of $D G \& C A 3$ and $D G \& C A 1$ arrangements were incubated in the continuous presence of $100 \mu \mathrm{M}$ SQ22536, $100 \mu \mathrm{M}$ Rp-cAMPs, or $10 \mu \mathrm{M}$ KT5720 for $14 \mathrm{~d}$ in vitro, and then synaptic responses were recorded from the CA3 stratum pyramidale in $D G \& C A 3$ cultures or from the CA1 stratum pyramidale in $D G \& C A 1$ slices after stimulation of the stratum granulosum of the DG explants. All of these inhibitors induced ectopic synaptogenesis within the CA1 pyramidal cells in the $D G \& C A 1$ cultures, whereas normal MF projections to the CA3 pyramidal cells in the $D G \& C A 3$ slices were virtually unaffected. ${ }^{* *} p<$ 0.01 versus Control slices; Tukey's test after ANOVA. Data are shown as means \pm SEM of $20-25$ slices. 

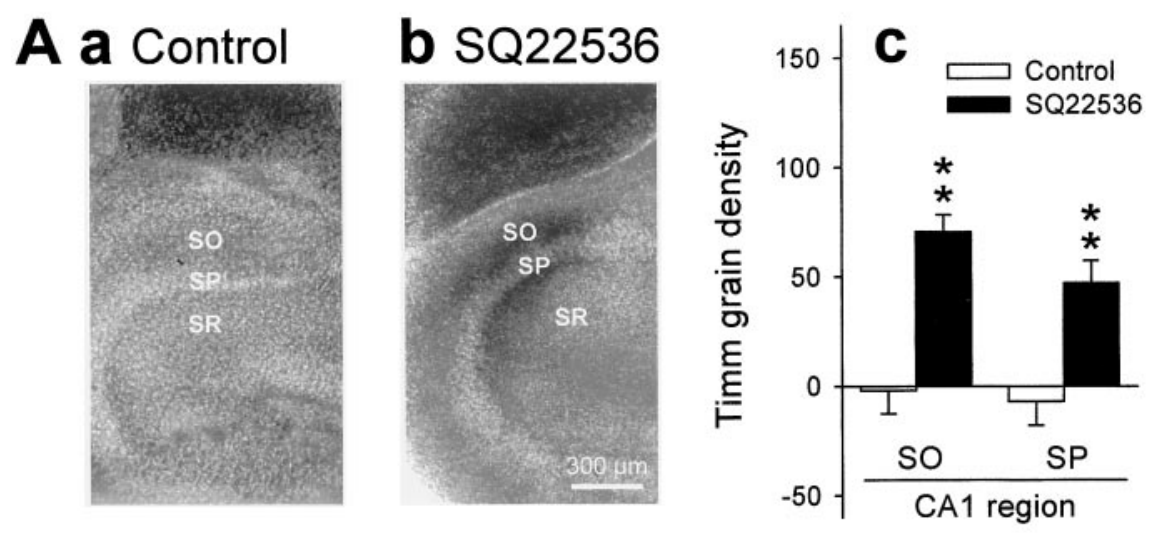

\section{B a Control} MF-CA1 synapse formation under low cAMP levels. DG and CA1 slices were cultured in the absence $(a)$ or presence $(b)$ of $100 \mu \mathrm{M}$ SQ22536 for $14 \mathrm{~d}$ in vitro. $A$, Timm staining indicated that evident MF terminals were detected in the CA1 region of SQ22536-treated cultures. Ac, Timm grain density was quantitatively analyzed in the CA1 stratum oriens $(S O)$ and the CA1 stratum pyramidale $(S P)$ of untreated (open columns) or SQ22536-treated slices (solid columns). ${ }^{* *} p<$ 0.01 versus Control slices; Tukey's test after ANOVA. Data are means \pm SEM of each of 10 slices. $B$, In SQ22536-treated cultures, DiIlabeled MFs elongated into the CA1 region of host hippocampal slices and formed varicositylike structures that were reminiscent of those seen in the CA3 region (Fig. 5). $C$, In the DG and CA1 cocultures grown in the presence of SQ22536, the optical signals of RH482 were propagated from the DG explants (\#) into the host hippocampal slices. All of these experiments were repeated at least five times, leading to similar results. $S R$, Stratum radiatum.

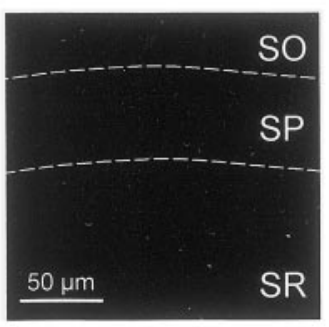

\section{b SQ22536}

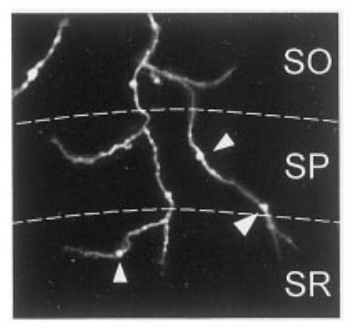

\section{C a Control}
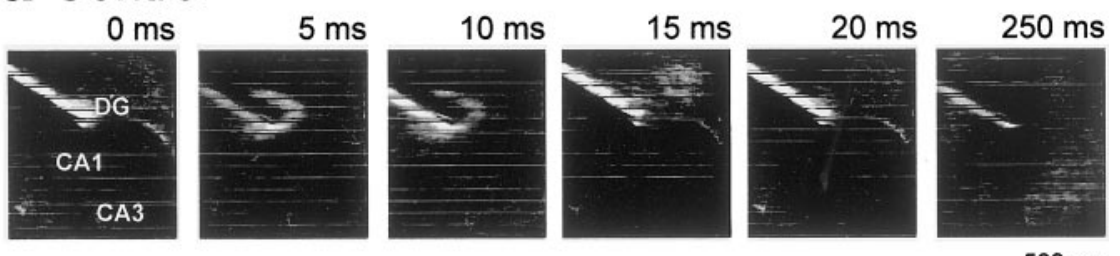

b SQ22536
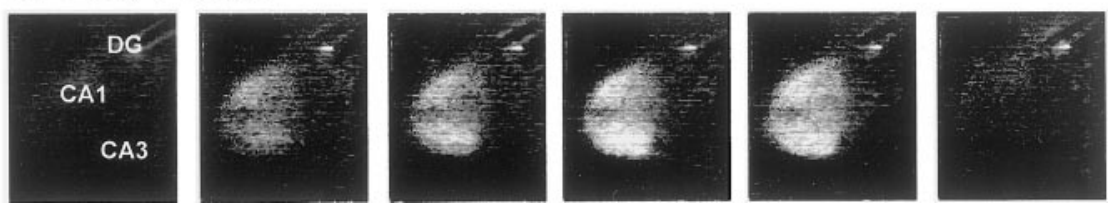

DG \& CA3 culture (Fig. 11A). Likewise, LY83583 inhibited MFCA3 synapse formation without inducing ectopic MF-CA1 synapses (Fig. 11 $A$ ). Timm staining of LY83583-treated cocultures revealed that MF terminals were sparsely distributed in the CA3 region, i.e., the stratum oriens as well as the stratum lucidum, suggesting that target-specific innervation of the MFs was collapsed by reduced cGMP levels (Fig. 11B). Similar results were obtained for coculture alignment of lesion (data not shown). Therefore, it is likely that the cGMP signaling pathway is required for selecting topographically correct targets. This idea was supported by the electrophysiological study, in which pharmacological blockade of cGMP/PKG signaling pathway did not completely abolish the MF-evoked synaptic responses, and $\sim 50 \%$ of fEPSP amplitude was still recorded from the target cells (Fig. 11A). This again suggests that under a low cGMP level, the MFs were not excluded from ingrowth into the host Ammon's horn slices but rather may lose their specific target, probably resulting in making synaptic contacts randomly. This idea was supported by the result from the slice overlay assay demonstrating that decreasing cGMP levels collapsed the directed MF elongation (Fig. 7C). Taken together, the cGMP system may serve to guide the MFs toward their accurate targets, whereas the cAMP system may serve to prevent them from elongating into incorrect targets.

One of the guanylyl cyclase activators is nitric oxide, a membrane-permeant neuronal messenger that is produced from L-arginine by the activation of nitric oxide synthase (Southam and Garthwaite, 1993). Very recently, Wagenen and Rehder (2001) reported that nitric oxide-mediated changes in growth cone morphology in cultured B5 Helisoma neurons depend on a soluble form of guanylyl cyclase. Therefore, the effect of $N^{\omega}$-nitro-Larginine methylester, an inhibitor of nitric oxide synthase, was examined; however, we found no evidence that nitric oxide synthase contributes to the MF development (data not shown).

Incidentally, electrophysiological studies indicated that the amplitude of fEPSP recorded from intact slices treated with drugs used here for $14 \mathrm{~d}$ was almost the same as that recorded from 


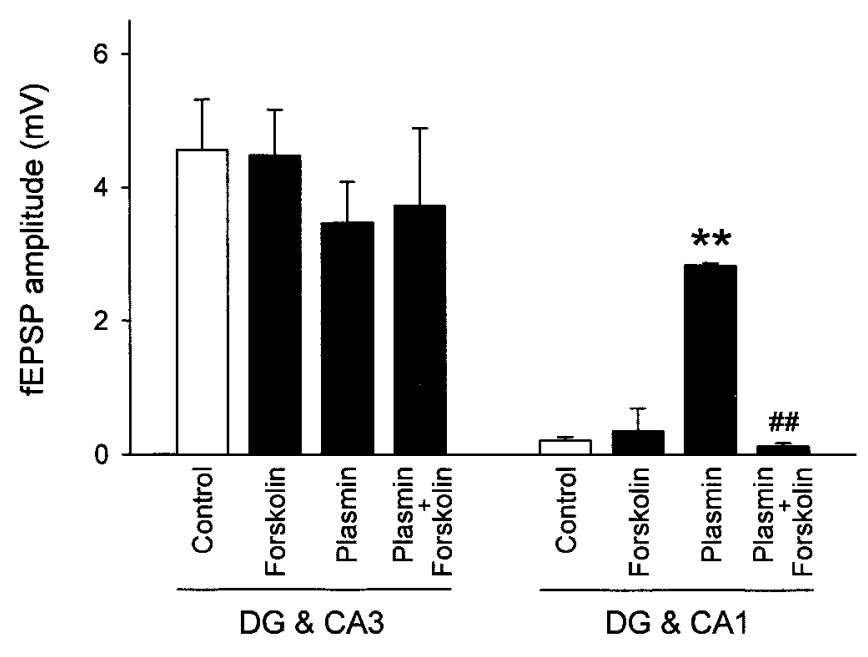

Figure 10. Treatment with plasmin disrupted MF axon guidance. Slices arranged in $D G \& C A 3$ and $D G \& C A 1$ patterns were cultivated in the presence of $100 \mu \mathrm{M}$ forskolin, $100 \mu \mathrm{M}$ plasmin, or a combination of 100 $\mu \mathrm{M}$ plasmin and $100 \mu \mathrm{M}$ forskolin for $14 \mathrm{~d}$ in vitro. Synaptic responses evoked by DG stimulation were recorded from CA3 stratum pyramidale in $D G \& C A 3$ cultures or from CA1 stratum pyramidale in $D G \& C A 1$ cultures. Plasmin treatment caused ectopic MF-CA1 synaptogenesis in the $D G \& C A 1$ cultures. This aberrant synapse formation was efficiently attenuated by forskolin. These agents did not affect normal MF projections to the CA3 pyramidal cells in the $D G \& C A 3$ slices. ** $p<0.01$ versus Control slices; Tukey's test after ANOVA. \#\# $p<0.01$ versus plasmin. The data represent the means \pm SEM of $20-25$ cases.

untreated slices (data not shown). In addition, neither PI labeling nor Nissl staining revealed apparent cell damages in any patterns of cocultures treated with any drugs (data not shown). These results suggest that $14 \mathrm{~d}$ exposures to these drugs had no apparent effects on neuron viability.

\section{DISCUSSION}

A fundamental issue in developmental neurobiology is how neurons establish precise connections to distant target cells. In the mammalian CNS, the hippocampal MFs have received much attention because of their unique features as follows. (1) The distribution of MF synapses is highly stereotyped and primarily restricted to a narrow strip along the proximal apical dendrites of CA3 pyramidal neurons, i.e., the stratum lucidum (Amaral and Dent, 1981; Henze et al., 2000); (2) MF network formation occurs not only in embryonic and early postnatal periods but also persists into adulthood because of prolonged proliferation of dentate granule cells (Kaplan and Hinds, 1977; Eckenhoff and Rakic, 1988; Kuhn et al., 1996); (3) epileptic conditions cause aberrant MF sprouting into the inner molecular layer and the stratum oriens (Sutula et al., 1989; Represa and Ben-Ari, 1992). Nonetheless, the mechanisms responsible for the topographic MF pathfinding are not well understood. In the present study, we addressed the cellular dynamics of MF outgrowth and found that the MFs use at least two discrete guidance cues to reach their correct target area. In addition, these guidance cues are likely to be independently regulated by cAMP and cGMP signaling pathways.

\section{Lamina-specific MF reinnervation}

In cocultures of tissue stumps of the DG and hippocampal Ammon's horn, the MFs were capable of regrowing into the appropriate target region (CA3) and forming new synaptic contacts with appropriate target pyramidal cells even when the normal MF course was disrupted by displaced arrangement of the excised slices. New synaptic contacts are made predominantly with the stratum lucidum. Therefore, extracellular guidance cues essential for lamina-specific MF development are retained in the isolated slices. In addition, Timm-stained terminals, their morphological specializations, and functional connections with CA3 pyramidal cells were also preserved in newly formed MF synapses. Hence, this coculture system is highly amenable for direct study of topographic MF growth and synaptogenesis.

Both slice overlay assay and coculture experiment demonstrated that the MFs grew away from the CA1 region and toward the CA3 region. These results alone cannot determine whether the MFs recognize a single or multiple guidance cues. However, the attractive behaviors of MFs toward the CA3 region and the avoidance from the CA1 region showed different susceptibilities to pharmacological inhibitors: the former was disturbed by cGMP/PKG inhibitors, and the latter was interfered with cAMP/ PKA blockers, but not vice versa. These differences can be explained by supposing that there are at least two distinct factors, i.e., an attractant derived from the CA3 region and a repellent from the CA1 region. This hypothesis was further supported by the result from the slice overlay assay indicating that the central region of Ammon's horn slices, probably the stratum lacunosum moleculare, is the neutral area where MFs showed no preference for orientation. This observation suggests that Ammon's horn slices do not have a gradient of a single guidance cue, but rather that the CA1 and CA3 regions are influenced separately by different guidance signals.

At the same time, however, the existence of the neutral area implies that the influence of the guidance cues is relatively short-range and spatially restricted. To determine whether these cue signals are diffusible or substrate-bound molecules, the DG explants were transplanted to fixed hippocampal slices. The MFs apparently did not invade the fixed host slices. Thus, it is possible that chemotropic molecules are involved in the MF pathfinding. On the other hand, our preliminary study using collagen-gel cocultures of CA1, CA3, and DG tissues has so far failed to find evidence for a potent diffusible factor affecting the direction of MF outgrowth. Therefore, we consider that membrane-bound molecules or short-range chemotropic molecules, or both, mediate the stereotyped MF extension.

Interestingly, when DG explants were opposed to the CA3 region of intact slices, no apparent MF synaptic responses were recorded from the target neurons, suggesting that ectopically arising MFs are unable to develop functional synaptic contacts with CA3 pyramidal cells having recipient sites that are occupied by extant MF inputs from the intrinsic DG. Further investigations will be required to determine whether MF-innervated pyramidal cells produce signals different from those made by the pyramidal cells waiting for MF innervation. Another series of experiments to elucidate these signals is now underway in our laboratory.

\section{Molecular mechanisms for cyclic nucleotide-mediated regulation of MF development}

Although the present study implies possible roles of cAMP and cGMP signaling pathways in MF development, our pharmacological experiments could not identify the sites where cAMP and cGMP act, i.e., MF growth cones, their target cells, or elsewhere. However, evident immunoreactivity for adenylyl cyclase was found in growth cones of developing MFs in cultured granule cells. Likewise, Wagenen and Rehder (2001) showed that guanylyl cyclase is also localized within growth cones of B5 Helisoma 
Figure 11. Involvement of the cGMP signaling pathway in MF synaptogenesis. Cocultures of $D G$ \& $C A 3$ and $D G \& C A 1$ arrangements were incubated in the presence of $100 \mathrm{nM}$ LY83583 or 100 $\mu \mathrm{M}$ Rp-pCPT-cGMPs for $14 \mathrm{~d}$ in vitro, and then synaptic responses evoked by DG stimulation were recorded from the CA3 region in $D G \& C A 3$ cultures or the CA1 region in $D G \& C A 1$ slices. These inhibitors reduced $\mathrm{MF}-\mathrm{CA} 3$ synaptic responses in the $D G \& C A 3$ cultures, whereas no MF projections to the CA1 region were observed in the $D G \&$ $C A 1$ slices. ${ }^{* *} p<0.01$ versus Control slices; Tukey's test after ANOVA. Data are shown as means \pm SEM of $20-25$ slices. $B$, Timm grain density was quantitatively analyzed in the CA3 stratum oriens $(S O)$, the CA3 stratum pyramidale $(S P)$, and the stratum lucidum $(S L)$ of untreated (open columns) or LY83583-treated slices (solid columns). ${ }^{*} p<0.05$ versus Control slices; Tukey's test after ANOVA. Data are means \pm SEM of each of 10-11 slices.
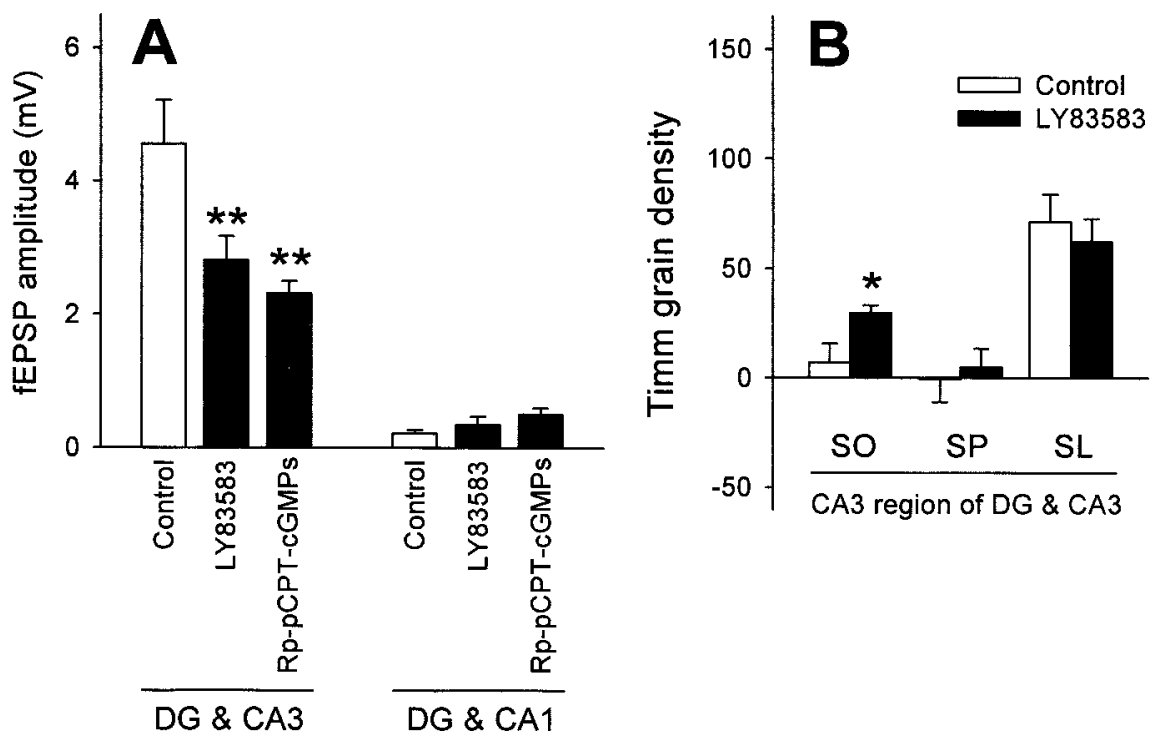

neurons. In addition, turning behaviors of isolated growth cones of Xenopus spinal neurons are changed by varying levels of cyclic nucleotides (Ming et al., 1997; Song et al., 1997, 1998), which provides direct evidence that cyclic nucleotides act within the growth cones. Therefore, we consider that cAMP and cGMP working in the growth cones regulate the target-specific MF guidance.

cAMP/PKA signaling pathway has been proposed to regulate growth cone behaviors of Xenopus spinal neurons (Ming et al., 1997; Song et al., 1997; Wang and Zheng, 1998). Consistent with this, we found that decreasing the cAMP level causes errant MF growth into the CA1 regions and ectopic synapse formation. Therefore, cAMP is likely to play a key role in repulsive responses of the MFs away from their inappropriate targets (CA1). Interestingly, the repulsive responses of granule cells cultured over the CA1 region were converted to attraction in the presence of adenylyl cyclase inhibitors. This result is somewhat analogous to several previous reports showing a cAMP-dependent switch of attractive/repulsive behaviors in response to brain-derived neurotrophic factor, acetylcholine (Song et al., 1997), Netrin (Ming et al., 1997; Hopker et al., 1999), and myelin-associated glycoprotein (Song et al., 1998) of Xenopus growth cones. In this context, our finding is the first evidence that the cAMP-dependent switch actually occurs for endogenous guidance cues present in the environment of mammalian tissues.

Although the mechanisms underlying cAMP-mediated regulation of growth cone behaviors have not been not fully determined, PKA is known to substrate inositol 1,4,5-trisphosphate receptors and the profilin-binding protein Mena, both of which are thought to mediate axon outgrowth and axon targeting (Takei et al., 1998; Lanier et al., 1999). RhoA, a member of the small GTP-binding proteins involved in regulating the cytoskeleton, is also a good substrate of PKA. The phosphorylation of RhoA is likely to prevent growth cone collapse in neuroblastoma (Kozma et al., 1997), pheochromocytoma PC12 cells (Tigyi et al., 1996), and dorsal root ganglia neurons (Jin and Strittmatter, 1997). Thus, these molecules may mediate MF repulsion against the CA1 region.

Our previous work demonstrated that pathologically excessive activation of voltage-sensitive L-type $\mathrm{Ca}^{2+}$ channels causes aberrant MF pathfinding (Ikegaya, 1999). The elevation of intracellular $\mathrm{Ca}^{2+}$ concentrations results in bidirectional, subtype-dependent changes in adenylyl cyclase activities, i.e., calmodulin-mediated activation of adenylyl cyclases types I and VIII, and direct inhibition of adenylyl cyclase types V and VI (Defer et al., 2000). Adenylyl cyclase type I is neurospecific and highly expressed in dentate granule cells (Xia et al., 1991, 1993), and its mutant mice show impaired long-term potentiation of MF-CA3 neurotransmission (Villacres et al., 1998). However, recent reports indicated that adenylyl cyclases types VI and VIII are also distributed in the CNS, including the hippocampus (Hellevuo et al., 1996; Liu et al., 1998). Therefore, it is unclear whether $\mathrm{Ca}^{2+}$ entry subsequently elicits an increase or decrease in cAMP level in MF growth cones. Furthermore, the fact that $\mathrm{cAMP} / \mathrm{PKA}$ activation induces the phosphorylation of L-type $\mathrm{Ca}^{2+}$ channels and thereby enhances the channel activity makes interpretation of the results difficult (Hosey et al., 1996; Gao et al., 1997). We think that the relationship between $\mathrm{Ca}^{2+}$ and cAMP in MF development cannot be deduced from our data alone.

Decreasing cGMP level resulted in a reduction of MF synaptic responses in the $\mathrm{CA} 3$ region. Thus, cGMP is likely to participate in the signal that attracts MFs toward their appropriate target. cGMP/PKG signaling pathways have been reported to regulate Sema3A- or Sema3D-mediated neurite orientation (Song et al., 1998; Polleux et al., 2000). Therefore, abundant expression of Sema3B, Sema3C, Sema3D, and Sema3F in the DG and the hippocampus is of particular interest (Skaliora et al., 1998; Steup et al., 2000). Indeed, Chen et al. (2000) reported a marked defect in MF projections in mutant mice lacking neuropilin-2, a receptor for Sema3C and Sema3F. Therefore, it is possible that the cGMPmediated MF guidance involves a common molecular mechanism for the neuropilin/Sema system.

In conclusion, we have shown for the first time that targetspecific MF outgrowth is performed by at least two distinct guidance cues that are regulated by cyclic nucleotide signaling pathways. Because our understanding of the intracellular events underlying MF development is still rudimentary, these findings may provide novel insights into the mechanisms of axon growth, axon targeting, and synapse formation in the MF system. 


\section{REFERENCES}

Abdel-Majid RM, Leong WL, Schalkwyk LC, Smallman DS, Wong ST, Storm DR, Fine A, Dobson MJ, Guernsey DL, Neumann PE (1998) Loss of adenylyl cyclase I activity disrupts patterning of mouse somatosensory cortex. Nat Genet 19:289-291.

Altman J, Das GD (1965) Autoradiographic and histological evidence of postnatal hippocampal neurogenesis in rats. J Comp Neurol 124:319-335

Amaral DG, Dent JA (1981) Development of the mossy fibers of the dentate gyrus: I. A light and electron microscopic study of the mossy fibers and their expansions. J Comp Neurol 195:51-86.

Baranes D, Lederfein D, Huang YY, Chen M, Bailey CH, Kandel ER (1998) Tissue plasminogen activator contributes to the late phase of LTP and to synaptic growth in the hippocampal mossy fiber pathway. Neuron 21:813-825.

Bonhoeffer F, Huf J (1980) Recognition of cell types by axonal growth cones in vitro. Nature 288:162-164.

Bray D, Hollenbeck PJ (1988) Growth cone motility and guidance. Annu Rev Cell Biol 4:43-61.

Chen H, Bagri A, Zupicich JA, Zou Y, Stoeckli E, Pleasure SJ, Lowenstein DH, Skarnes WC, Chedotal A, Tessier-Lavigne M (2000) Neuropilin-2 regulates the development of select cranial and sensory nerves and hippocampal mossy fiber projections. Neuron 25:43-56.

Dailey ME, Buchanan J, Bergles DE, Smith SJ (1994) Mossy fiber growth and synaptogenesis in rat hippocampal slices in vitro. J Neurosci $14: 1060-1078$.

Defer N, Best-Belpomme M, Hanoune J (2000) Tissue specificity and physiological relevance of various isoforms of adenylyl cyclase. Am J Physiol Renal Physiol 279:F400-416.

Eckenhoff MF, Rakic P (1988) Nature and fate of proliferative cells in the hippocampal dentate gyrus during the life span of the rhesus monkey. J Neurosci 8:2729-2747.

Eriksson PS, Perfilieva E, Bjork-Eriksson T, Alborn A, Nordborg C, Peterson DA, Gage FH (1998) Neurogenesis in the adult human hippocampus. Nat Med 4:1313-1317.

Gähwiler BH (1984) Slice cultures of cerebellar, hippocampal and hypothalamic tissue. Experientia 40:235-243.

Gaiarsa JL, Heimrich B (1995) Restoration of mossy fiber projection in slice co-cultures of dislocated dentate gyrus and degranulated hippocampus. Dev Brain Res 86:250-258.

Gao T, Yatani A, Dell'Acqua ML, Sako H, Green SA, Dascal N, Scott JD, Hosey MM (1997) cAMP-dependent regulation of cardiac L-type $\mathrm{Ca}^{2+}$ channels requires membrane targeting of PKA and phosphorylation of channel subunits. Neuron 19:185-196.

Gundersen RW, Barrett JN (1979) Neuronal chemotaxis: chick dorsal root axons turn towards high concentrations of nerve growth factor. Science 206:1079-1080

Hellevuo K, Hoffman PL, Tabakoff B (1996) Adenylyl cyclases: mRNA and characteristics of enzyme activity in three areas of brain. J Neurochem 67:177-185.

Henze DA, Urban NN, Barrionuevo G (2000) The multifarious hippocampal mossy fiber pathway: a review. Neuroscience 98:407-427.

Honig MG, Hume RI (1989) Dil and DiO: versatile fluorescent dyes for neuronal labeling and pathway tracing. Trends Neurosci 12:333-341.

Hopker VH, Shewan D, Tessier-Lavigne M, Poo MM (1999) Growthcone attraction to netrin-1 is converted to repulsion by laminin- 1 . Nature 401:69-73.

Hosey MM, Chien AJ, Puri TS (1996) Structure and regulation of L-type calcium channels: a current assessment of the properties and roles of channel subunits. Trends Cardiovasc Med 6:265-273.

Huang YY, Li XC, Kandel E (1994) cAMP contributes to mossy fiber LTP by initiating both a covalently mediated early phase and macromolecular synthesis-dependent late phase. Cell 79:69-79.

Ikegaya Y (1999) Abnormal targeting of developing hippocampal mossy fibers after epileptiform activities via L-type $\mathrm{Ca}^{2+}$ channel activation in vitro. J Neurosci 19:802-812.

Ikegaya Y, Yoshida M, Saito H, Nishiyama N (1997) Epileptic activity prevents synapse formation of hippocampal mossy fibers via L-type calcium channel activation in vitro. J Pharmacol Exp Ther 280:471-476

Ikegaya Y, Ikeda Y, Saito H, Nishiyama N (1998) Suppression of synaptogenesis by epileptiform discharges in hippocampal slice culture. Biol Pharm Bull 2:231-234

Jin Z, Strittmatter SM (1997) Rac1 mediates collapsin-1-induced growth cone collapse. J Neurosci 17:6256-6263.

Kaplan MS, Hinds JW (1977) Neurogenesis in adult rat: electron microscopic analysis of light radioautographs. Science 197:1092-1094.

Keynes R, Cook GWW (1995) Axon guidance molecules. Cell 83:161-169.

Kozma R, Sarner S, Ahmed S, Lim L (1997) Rho family GTPases and neuronal growth cone remodeling: relationship between increased complexity induced by $\mathrm{Cdc} 42 \mathrm{Hs}$, Rac1, and acetylcholine and collapse induced by RhoA and lysophosphatidic acid. Mol Cell Biol 17:1201-1211.
Kuhn HG, Dickinson-Anson H, Gage FH (1996) Neurogenesis in the dentate gyrus of the adult rat: age-related decrease of neuronal progenitor proliferation. J Neurosci 16:2027-2033.

Lanier LM, Gates MA, Witke W, Menzies AS, Wehman AM, Macklis JD, Kwiatkowski D, Soriano P, Gertler FB (1999) Mena is required for neurulation and commissure formation. Neuron 22:313-325.

Liu FC, Wu GC, Hsieh ST, Lai HL, Wang HF, Wang TW, Chern Y (1998) Expression of type VI adenylyl cyclase in the central nervous system: implication for a potential regulator of multiple signals in different neurotransmitter systems. FEBS Lett 436:92-98.

Macklis JD, Madison RD (1990) Progressive incorporation of propidium iodide in cultured mouse neurons correlates with declining electrophysiological status: a fluorescence scale of membrane integrity. J Neurosci Methods 31:43-46.

Ming GL, Song HJ, Berninger B, Holt CE, Tessier-Lavigne M, Poo MM (1997) cAMP-dependent growth cone guidance by netrin-1. Neuron $19: 1225-1235$

Müller BK (1999) Growth cone guidance: first steps towards a deeper understanding. Annu Rev Neurosci 22:351-388.

Muller D, Buchs PA, Stoppini L (1993) Time course of synaptic development in hippocampal organotypic cultures. Dev Brain Res 71:93-100.

Muller D, Stoppini L, Wang C, Kiss JZ (1994) A role for polysialylated neural cell adhesion molecule in lesion-induced sprouting in hippocampal organotypic cultures. Neuroscience 61:441-445.

Nakagami Y, Saito H, Matsuki N (1997) Optical recording of trisynaptic pathway in rat hippocampal slices with a voltage-sensitive dye. Neuroscience 81:1-8.

Nguyen LB, Ricciardi TN, Malouf AT (1996) Reinnervation of stratum lucidum by hippocampal mossy fibers is developmentally regulated. Dev Brain Res 95:184-193.

Parent JM, Yu TW, Leibowitz RT, Geschwind DH, Sloviter RS, Lowenstein DH (1997) Dentate granule cell neurogenesis is increased by seizures and contributes to aberrant network reorganization in the adult rat hippocampus. J Neurosci 17:3727-3738.

Pimenta AF, Zhukareva V, Barbe MF, Reinoso BS, Grimley C, Henzel W, Fischer I, Levitt P (1995) The limbic system-associated membrane protein is an Ig superfamily member that mediates selective neuronal growth and axon targeting. Neuron 15:287-297.

Polleux F, Giger RJ, Ginty DD, Kolodkin AL, Ghosh A (1998) Patterning of cortical efferent projections by Semaphorin-Neuropilin interactions. Science 282:1904-1906.

Polleux F, Morrow T, Ghosh A (2000) Semaphorin 3A is a chemoattractant for cortical apical dendrites. Nature 404:567-573.

Ramón y Cajal S (1911) Histologie du système nerveux de l'homme et des vertébrés, Vol I and II. Madrid: Consejo Superior de Investigaciones Cientificas.

Represa A, Ben-Ari Y (1992) Kindling is associated with the formation of novel mossy fibre synapses in the CA3 region. Brain Res 92:69-78

Seki T, Rutishauser U (1998) Removal of polysialic acid-neural cell adhesion molecule induces aberrant mossy fiber innervation and ectopic synaptogenesis in the hippocampus. J Neurosci 18:3757-3766.

Sherry S (1968) Fibrinolysis. Annu Rev Med 19:247-268.

Skaliora I, Singer W, Betz H, Puschel AW (1998) Differential patterns of semaphorin expression in the developing rat brain. Eur $\mathbf{J}$ Neurosci 10:1215-1229.

Song HJ, Ming GL, Poo MM (1997) cAMP-induced switching in turning direction of nerve growth cones. Nature 388:275-279.

Song HJ, Ming GL, He Z, Lehmann M, McKerracher L, Tessier-Lavigne M. Poo MM (1998) Conversion of neuronal growth cone responses from repulsion to attraction by cyclic nucleotides. Science 281:1515-1518.

Southam E, Garthwaite J (1993) The nitric oxide-cyclic GMP signaling pathway in rat brain. Neuropharmacology 32:1267-1277.

Steup A, Lohrum M, Hamscho N, Savaskan NE, Ninnemann O, Nitsch R, Fujisawa H, Puschel AW, Skutella T (2000) Sema3C and Netrin-1 differentially affect axon growth in the hippocampal formation. Mol Cell Neurosci 15:141-155.

Stoppini L, Buchs PA, Müller D (1991) A simple method for organotypic cultures of nervous tissue. J Neurosci Methods 37:173-182.

Sutula T, Cascino G, Cavazos J, Parada I, Ramirez L (1989) Mossy fiber synaptic reorganization in the epileptic human temporal lobe. Ann Neurol 26:321-330.

Takei K, Shin RM, Inoue T, Kato K, Mikoshiba K (1998) Regulation of nerve growth mediated by inositol 1,4,5-trisphosphate receptors in growth cones. Science 282:1705-1708.

Tessier-Lavigne M, Goodman CS (1996) The molecular biology of axon guidance. Science 274:1123-1133.

Tessier-Lavigne M, Placzek M, Lumsden AG, Dodd J, Jessell TM (1988) Chemotropic guidance of developing axons in the mammalian central nervous system. Nature 336:775-778.

Tigyi G, Fischer DJ, Sebok A, Yang C, Dyer DL, Miledi R (1996) Lysophosphatidic acid-induced neurite retraction in PC12 cells: contro by phosphoinositide- $\mathrm{Ca}^{2+}$ signaling and Rho. J Neurochem 66:537-548. 
Tzounopoulos T, Janz R, Sudhof TC, Nicoll RA, Malenka RC (1998) A role for cAMP in long-term depression at hippocampal mossy fiber synapses. Neuron 21:837-845.

Villacres EC, Wong ST, Chavkin C, Storm DR (1998) Type I adenylyl cyclase mutant mice have impaired mossy fiber long-term potentiation. J Neurosci 18:3186-3194

Wagenen SV, Rehder V (2001) Regulation of neuronal growth cone filopodia by nitric oxide depends on soluble guanylyl cyclase. J Neurobiol 46:206-219.

Wang Q, Zheng JQ (1998) cAMP-mediated regulation of neurotrophininduced collapse of nerve growth cones. J Neurosci 18:4973-4984.

Weisskopf MG, Castillo PE, Zalutsky RA, Nicoll RA (1994) Mediation of hippocampal mossy fiber long-term potentiation by cyclic AMP. Science 265:1878-1882

Wu YP, Siao CJ, Lu W, Sung TC, Frohman MA, Milev P, Bugge TH, Degen JL, Levine JM, Margolis RU, Tsirka SE (2000) The tissue plasminogen activator (tPA)/plasmin extracellular proteolytic system regulates seizure-induced hippocampal mossy fiber outgrowth through a proteoglycan substrate. J Cell Biol 148:1295-1304.

Xia Z, Refsdal CD, Merchant KM, Dorsa DM, Storm DR (1991) Distribution of mRNA for the calmodulin-sensitive adenylate cyclase in rat brain: expression in areas associated with learning and memory. Neuron $6: 431-443$.

Xia Z, Choi EJ, Wang F, Blazynski C, Storm DR (1993) Type I calmodulin-sensitive adenylyl cyclase is neural specific. J Neurochem 60:305-311

Yamamoto N, Higashi S, Toyama K (1997) Stop and branch behaviors of geniculocortical axons: a time-lapse study in organotypic cocultures. J Neurosci 17:3653-3663.

Zimmer J, Gähwiler BH (1987) Growth of hippocampal mossy fibers: a lesion and coculture study of organotypic slice cultures. J Comp Neurol 264:1-13. 